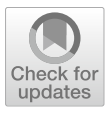

Cite as

Nano-Micro Lett.

(2022) 14:25

Received: 4 August 2021

Accepted: 8 October 2021

Published online: 10 December 2021

(C) The Author(s) 2021

\section{Atomically Dispersed Fe-Co Bimetallic Catalysts for the Promoted Electroreduction of Carbon Dioxide}

\author{
Zhangsen Chen ${ }^{1}$, Gaixia Zhang ${ }^{1}$, Yuren $\mathrm{Wen}^{2}$, Ning $\mathrm{Chen}^{3}$, Weifeng Chen ${ }^{3}$,

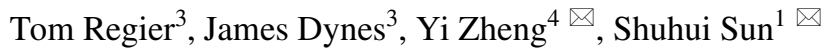

\title{
HIGHLIGHTS
}

- X-ray photoelectron spectroscopy results confirmed the increased number of M-N sites in the bimetallic Fe-Co catalyst.

- Synchrotron-based X-ray absorption fine structure demonstrated that the interaction in the coordination environments of the different transition metal sites facilitated the $\mathrm{CO}$ production in electroreduction reaction of $\mathrm{CO}_{2}\left(\mathrm{ECO}_{2} \mathrm{RR}\right)$.

- This bimetallic strategy has also been extended to fabricate other catalysts such as $\mathrm{Cu}-\mathrm{Co}$ and $\mathrm{Ni}-\mathrm{Co}$, which also exhibited enhanced performance for $\mathrm{ECO}_{2} \mathrm{RR}$.

ABSTRACT The electroreduction reaction of $\mathrm{CO}_{2}\left(\mathrm{ECO}_{2} \mathrm{RR}\right)$ requires high-performance catalysts to convert $\mathrm{CO}_{2}$ into useful chemicals. Transition metal-based atomically dispersed catalysts are promising for the high selectivity and activity in $\mathrm{ECO}_{2} \mathrm{RR}$. This work presents a series of atomically dispersed $\mathrm{Co}, \mathrm{Fe}$ bimetallic catalysts by carbonizing the $\mathrm{Fe}$-introduced Co-zeolitic-imidazolate-framework (C-Fe-Co-ZIF) for the syngas generation from $\mathrm{ECO}_{2} \mathrm{RR}$. The synergistic effect of the bimetallic catalyst promotes $\mathrm{CO}$ production. Compared to the pure $\mathrm{C}-$ $\mathrm{Co}-\mathrm{ZIF}, \mathrm{C}-\mathrm{Fe}-\mathrm{Co}-\mathrm{ZIF}$ facilitates $\mathrm{CO}$ production with a $\mathrm{CO}$ Faradaic efficiency (FE) boost of $10 \%$, with optimal $\mathrm{FE}_{\mathrm{CO}}$ of $51.9 \%, \mathrm{FE}_{\mathrm{H} 2}$ of

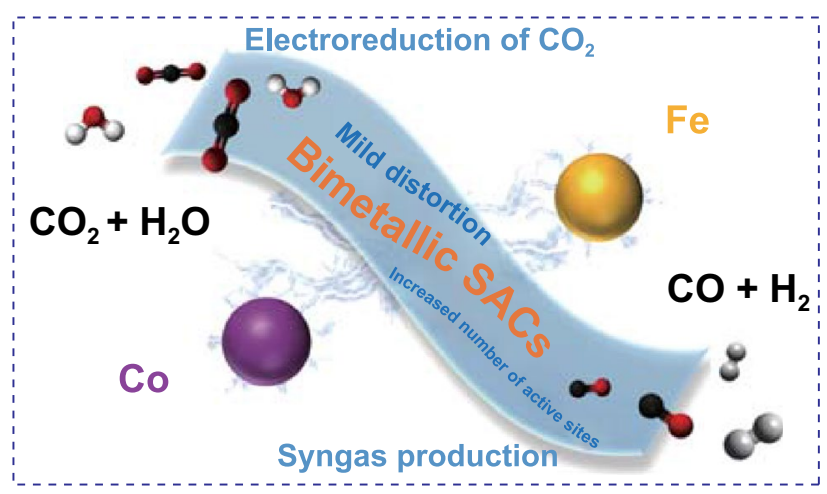
$42.4 \%$ at $-0.55 \mathrm{~V}$, and $\mathrm{CO}$ current density of $8.0 \mathrm{~mA} \mathrm{~cm}{ }^{-2}$ at $-0.7 \mathrm{~V}$ versus reversible hydrogen electrode (RHE). The $\mathrm{H}_{2} / \mathrm{CO}$ ratio is tunable from 0.8 to 4.2 in a wide potential window of -0.35 to $-0.8 \mathrm{~V}$ versus RHE. The total $\mathrm{FE}_{\mathrm{CO}+\mathrm{H} 2}$ maintains as high as $93 \%$ over $10 \mathrm{~h}$. The proper adding amount of Fe could increase the number of active sites and create mild distortions for the nanoscopic environments of $\mathrm{Co}$ and $\mathrm{Fe}$, which is essential for the enhancement of the $\mathrm{CO}$ production in $\mathrm{ECO}_{2} \mathrm{RR}$. The positive impacts of $\mathrm{Cu}-\mathrm{Co}$ and $\mathrm{Ni}-\mathrm{Co}$ bimetallic catalysts demonstrate the versatility and potential application of the bimetallic strategy for $\mathrm{ECO}_{2} \mathrm{RR}$.

KEYWORDS $\mathrm{CO}_{2}$ reduction; Electrocatalysis; Syngas production; Cobalt; Iron; Bimetallic catalysts

\footnotetext{
Gaixia Zhang, gaixia.zhang@emt.inrs.ca; Yi Zheng, yizheng@fzu.edu.cn; Shuhui Sun, shuhui@emt.inrs.ca

Institut National de la Recherche Scientifique-Énergie Matériaux et Télécommunications, Varennes, QC J3X 1P7, Canada

2 School of Materials Science and Engineering, University of Science and Technology, 100083 Beijing, People's Republic of China

3 Canadian Light Source, University of Saskatchewan, Saskatoon, SK S7N 2V3, Canada

4 Research Institute of Photocatalysis, State Key Laboratory of Photocatalysis on Energy and Environment, Fuzhou University, Fuzhou 350116, People's Republic of China
} 


\section{Introduction}

More and more anthropogenic activities depend on the consumption of fossil fuels, which increasingly causes the energy crisis and excessive carbon dioxide $\left(\mathrm{CO}_{2}\right)$ emissions. The latter greatly contributes to the acceleration of global warming. The reduction reaction of $\mathrm{CO}_{2}\left(\mathrm{CO}_{2} \mathrm{RR}\right)$, i.e., the conversion of $\mathrm{CO}_{2}$ into value-added chemicals and fuels, provides a promising alternative to the solution for the energy crisis and global warming [1]. The electroreduction reaction of $\mathrm{CO}_{2}\left(\mathrm{ECO}_{2} \mathrm{RR}\right)$ contains advantages because of the great potential in future commercialization including renewable energy-generated electricity and easy scale-up. One of the most economic reduction products from $\mathrm{ECO}_{2} \mathrm{RR}$, carbon monoxide $(\mathrm{CO})$ that is the main component of syngas (gas mixture of $\mathrm{CO}$ and $\mathrm{H}_{2}$ ) attracts considerable attention [2]. $\mathrm{CO}$ or syngas produced from $\mathrm{ECO}_{2} \mathrm{RR}$ can be applied as feedstock in established industrial processes (e.g., Fischer-Tropsch synthesis) for the production of various important chemicals, such as long-chain hydrocarbons, methanol, higher alcohols, and fuels [3-5]. CO production from $\mathrm{ECO}_{2} \mathrm{RR}$ could contribute to the conception of completing the carbon loop, which could benefit the sustainable development of human society.

To fulfill the industrialization of $\mathrm{ECO}_{2} \mathrm{RR}$, it requires noble-metal-free-based catalysts to cut the cost while maintaining high catalytic efficiency. The state-of-art $\mathrm{ECO}_{2} \mathrm{RR}$ catalyst design focuses on metal-based catalysts. For example, $\mathrm{Cu}$-based catalysts are exclusively effective for the production of alcohols/hydrocarbons; $\mathrm{Ag}$, $\mathrm{Au}$, and $\mathrm{Zn}$, or most recently the atomically dispersed $\mathrm{M}-\mathrm{N}-\mathrm{C}$ catalysts are efficient for CO production [6, 7]. Single-atom catalysts (SACs) are known for their efficient active sites, maximized utilization of metal atoms, and low cost. Typical SACs, such as Co- $\mathrm{N}_{\mathrm{x}}[8,9]$, atomically $\mathrm{Ni}$ or Fe-dispersed nitrogen-doped graphene [10, 11], and $\mathrm{Fe}-\mathrm{N}-\mathrm{C}$ [12], have revealed highly efficient $\mathrm{CO}$ production in $\mathrm{ECO}_{2} \mathrm{RR}$ attributed to the unique coordination environment of single-atom sites. The direct $\mathrm{ECO}_{2} \mathrm{RR}$ production of syngas with different $\mathrm{H}_{2} / \mathrm{CO}$ ratios could be highly desirable for various downstream products in Fischer - Tropsch synthesis and other thermochemical processes, compared to the traditional industrial methods (e.g., reforming of natural gas and coal, the water gas shift reaction), which demand relatively harsh reaction conditions at high-cost $[13,14]$. SACs, such as atomically dispersed $\mathrm{Ni}$ catalysts [15], and nickel@nitrogen-doped carbon nanotubes
[16], also demonstrate excellent syngas production performance. In recent years, bimetallic catalyst materials in many mainstream reactions have been developed. The hybrid alloy structures of $\mathrm{NiCo}$ and $\mathrm{FeNi}$ benefit oxygen reduction reaction (ORR) and oxygen evolution reaction (OER), while the synergistic effects between $\mathrm{Pd}$ and $\mathrm{CoO}_{\mathrm{x}}$ promoting $\mathrm{CO}$ oxidation [17-19]. The interaction of different metal-sites with the modification of the foreign metal could improve the intrinsic catalytic activity of $\mathrm{ECO}_{2} \mathrm{RR}$ in bimetallic catalysts [20]. $\mathrm{Pd} / \mathrm{NbN}$ promotes the formation of $\mathrm{PdH}$ during the $\mathrm{ECO}_{2} \mathrm{RR}$ process, leading to the enhancement of syngas production [21]. The combinations of TMs $\mathrm{Co}, \mathrm{Ni}$, and Fe with noble-metal Ag create the synergism that increases the tenability of syngas ratio in syngas production from $\mathrm{ECO}_{2} \mathrm{RR}$ [22].

The strategy of utilizing noble-metal-free catalyst materials has advantages of the synergistic effects of different metal sites in bimetallic TM-catalysts, the augmented production rate of syngas, and tunable ratios of $\mathrm{CO} / \mathrm{H}_{2}$. Chen et al. fabricated bimetallic $\mathrm{Co}$, Ni SACs for syngas production from $\mathrm{ECO}_{2} \mathrm{RR}$ [23]. Benefiting from the individual selectivity toward $\mathrm{H}_{2}$ and $\mathrm{CO}$ for $\mathrm{Co}$ and $\mathrm{Ni}$, respectively, the final CoNi bimetallic catalyst exhibited the tunable $\mathrm{H}_{2} /$ $\mathrm{CO}$ ratios of $0.8-1.3$ in the reduction product [23]. It is worthwhile for the extensive exploration, especially in the earth-abundant $\mathrm{TM}$ elements such as $\mathrm{Fe}, \mathrm{Co}, \mathrm{Ni}$, and $\mathrm{Cu}$ for syngas production with tunable $\mathrm{H}_{2} / \mathrm{CO}$ ratios in $\mathrm{ECO}_{2} \mathrm{RR}$. The classic bimetallic catalysts are alloy catalysts where two different metals are well intermixed and in close proximity/ coordination to each other, thus promoting catalytic performance. The situation is very different in atomically dispersed $\mathrm{M}-\mathrm{N}-\mathrm{C}$ catalysts with different types of metals present. Further researches are ongoing to investigate whether the different M-N-C sites in the bimetallic atomically dispersed catalysts working separately or there is an interaction between them like the alloy catalysts [24]. The objectives of the present study are to design bimetallic atomically dispersed catalysts, investigate the interaction between different metal sites and the contribution to the performance of $\mathrm{ECO}_{2} \mathrm{RR}$.

Here, we report a bimetallic catalyst with atomically dispersed $\mathrm{Co}$ and $\mathrm{Fe}$ sites for the highly efficient $\mathrm{ECO}_{2} \mathrm{RR}$ for syngas production, which is our preliminary attempt to understand the interaction between $\mathrm{Co}$ and $\mathrm{Fe}$ and its contribution to the catalytic performance. The bimetallic catalysts are fabricated by using a zeolitic imidazolate framework (ZIF-8) as the precursor, which is a metal-organic 
framework (MOF) that is tunable in metal nodes [8]. The Co-ZIF is first constructed on ZIF precursor, followed by the introduction of $\mathrm{Fe}$. The introduction of $\mathrm{Fe}$ into $\mathrm{Co}-\mathrm{ZIF}$ $(\mathrm{Fe}-\mathrm{Co}-\mathrm{ZIF})$ creates the interaction between $\mathrm{Co}$ and $\mathrm{Fe}$ sites in the final carbonized catalysts (C-Fe-Co-ZIF- $x, x$ is the adding amount of $\mathrm{Fe}$ (wt $\%$ ) in the ZIF precursor). X-ray photoelectron spectroscopy (XPS) illustrates that the introduction of $\mathrm{Fe}$ with the proper amount could increase the number of $\mathrm{M}-\mathrm{N}$ sites in the catalyst, promoting the $\mathrm{ECO}_{2} \mathrm{RR}$ performance. The interactions of different TMs in the bimetallic catalysts are indicated by X-ray absorption spectroscopy (XAS). It confirms that the coordination environment of Co is distorted by the addition of $\mathrm{Fe}$ in the bimetallic catalysts. Electrochemical measurements are carried out to investigate the catalytic performance of $\mathrm{C}-\mathrm{Fe}-\mathrm{Co}-\mathrm{ZIFs}$. C-Fe-Co-ZIF$1.6 \mathrm{wt} \%-\mathrm{Fe}$ that has the mild distortions in $\mathrm{Co}-\mathrm{N}$ and $\mathrm{Fe}-\mathrm{N}$ sites exhibits the best $\mathrm{ECO}_{2} \mathrm{RR}$ performance toward $\mathrm{CO}$ production while maintaining the high total $\mathrm{FE}_{\mathrm{CO}+\mathrm{H} 2}$ of around $93 \%$ for more than $10 \mathrm{~h} . \mathrm{Cu}-\mathrm{Co}$ and Ni-Co bimetallic catalysts (carbonized $\mathrm{Cu}$ and Ni-modified $\mathrm{Co}-\mathrm{ZIF}$ ) are confirmed to be able to promote $\mathrm{ECO}_{2} \mathrm{RR}$ performance, demonstrating the versatility of the bimetallic SACs strategy. This work systematically investigates the interaction between different metals in bimetallic atomically dispersed catalysts for $\mathrm{ECO}_{2} \mathrm{RR}$, providing interesting insights into the design of the catalyst for the next generation.

\section{Experimental Section}

\subsection{Instruments}

The X-ray diffraction (XRD) patterns were collected on an $\mathrm{X}$-ray diffractometer (Bruker D8 Advance) with a $\mathrm{CuK} \alpha$ X-ray source $(\lambda=1.542 \AA)$ and a scintillator detector. Scanning electron microscopy (SEM) images were obtained using a focused ion beam and scanning electron microscope (Tescan LYRA $3 \mathrm{XMH}$ ) at $20 \mathrm{kV}$. Transmission electron microscopy (TEM) was performed on a JEOL ARM200F operated at $200 \mathrm{kV}$. For atomic resolution imaging, the measurements were performed under HAADF-STEM mode. Samples for TEM were prepared by drop-drying the samples from their diluted ethanol suspensions onto carbon-coated copper grids. Inductively coupled plasma-optical emission spectrometry (ICP-OES) results were obtained by an Agilent 5100 ICP-OES. XPS experiments were undertaken on a VG Escalab 220i XL using monochromatic $1486.6 \mathrm{eV}$ Al $\mathrm{K} \alpha$ radiation. The peak energies were calibrated by placing the graphite $\mathrm{C} 1 \mathrm{~s}$ peak at $284.8 \mathrm{eV}$. The spectra were fitted with mixed Gaussian-Lorentzian component profiles after a Shirley background subtraction by CasaXPS software. X-ray absorption spectroscopy including X-ray absorption nearedge spectra (XANES) and extended X-ray absorption fine structure (EXAFS) at Co K-edge and Fe-K-edge were collected in total-fluorescence-yield mode using a 32-element Ge detector at ambient condition on the 06ID-1 Hard X-ray MicroAnalysis (HXMA) beamline at the Canadian Light Source (CLS). During the data collection, the CLS storage ring $(2.9 \mathrm{GeV})$ was operated under $250 \mathrm{~mA}$ mode and the HXMA superconducting wiggler was run at $1.9 \mathrm{~T}$. The scan range was kept in an energy range of 7510-8350 eV for Co K-edge and 6910-7755 eV for Fe K-edge. Data collection configuration was using metal $\mathrm{Co}$ and $\mathrm{Fe}$ foils as energy calibrations by in step calibration for every data set. The baseline of pre-edge was subtracted and the post-edge was normalized in the spectra. EXAFS analysis was conducted using Fourier transform on $\mathrm{k}^{3}$-weighted EXAFS oscillations to evaluate the contribution of each bond pair to Fourier transform peak. The XANES of N K-edge, Co L-edge, and $\mathrm{Fe}$ L-edge were measured in total $\mathrm{X}$-ray electron yield mode at room temperature on the 11ID-1 High-Resolution Spherical Grating Monochromator (SGM) beamline at the CLS, while the samples were subjected in an ultrahigh vacuum chamber. Pure metals such as Co and Fe were used as the reference to calibrate the energy for every data set.

\subsection{Electrochemical Measurements}

Catalyst electrodes were prepared by dropping the catalyst ink onto the carbon paper (Sigracet $25 \mathrm{BC}$ ) with a fixed area of $1 \mathrm{~cm}^{2}$. The catalyst ink was prepared by mixing $0.5 \mathrm{mg}$ of the catalyst powder, $120 \mu \mathrm{L}$ of DI water, $120 \mu \mathrm{L}$ of ethanol, and $2 \mu \mathrm{L}$ of Nafion ${ }^{\circledR}$ perfluorinated resin solution ( $5 \mathrm{wt} \%$, Sigma). The mixture was treated with ultrasound for $30 \mathrm{~min}$ and dropped onto the carbon paper on an $80{ }^{\circ} \mathrm{C}$ hot plate. The electrode was finally dried under $70{ }^{\circ} \mathrm{C}$ in an oven for further experiments.

Cyclic voltammetry $(\mathrm{CV}$, performed at the scan rate of $20 \mathrm{mV} \mathrm{s}^{-1}$ ), linear sweeping voltammetry (LSV, performed at the scan rate of $5 \mathrm{mV} \mathrm{s}^{-1}$ ), the chronoamperometry test, double-layer capacitance, and the electrochemical 
impedance spectroscopy (EIS, performed at open circuit potential with a high frequency of 100,000 and low frequency of 0.01 ) were carried out in a custom-made twochamber H-type cell on a CHI 760D electrochemical workstation with the catalyst electrode as the working electrode. Working and reference electrodes were fixed in one chamber and the counter electrode was fixed in the other chamber. A proton exchange membrane (Nafion ${ }^{\mathrm{TM}} \mathrm{N} 115$ ) separated the two chambers of the $\mathrm{H}$-cell. The reference electrode was an $\mathrm{Ag} / \mathrm{AgCl}$ electrode with a saturated $\mathrm{KCl}$ filling solution. The counter electrode was a Pt wire. Potential versus reversible hydrogen electrode (RHE) was calculated as E versus $\mathrm{RHE}=\mathrm{E}$ versus $\mathrm{Ag} / \mathrm{AgCl}+0.197 \mathrm{~V}+0.0592 \mathrm{~V} \times \mathrm{pH}$. The $\mathrm{pH}$ values of $\mathrm{CO}_{2}$ and $\mathrm{N}_{2}$-saturated $0.5 \mathrm{M} \mathrm{KHCO}_{3}$ electrolyte used in this work are 7.23 and 8.36, respectively. Unless notified elsewhere, the automatic iR compensation (80\%) was applied to all the measurements.

During the electrochemical tests, each chamber of the $\mathrm{H}$-cell was filled with $40 \mathrm{~mL} 0.5 \mathrm{M} \mathrm{KHCO}_{3}$ electrolyte. $\mathrm{CO}_{2}$ (Praxair, 99.99\%) (or $\mathrm{N}_{2}$ (Praxair, 99.999\%) for the blank experiments) was bubbled through the electrolyte in the working electrode chamber with a flow rate of 20 standard cubic centimeters per minute (SCCM) at least $30 \mathrm{~min}$ before the tests. The gas outlet was introduced into a gas-sampling loop of the gas chromatography (GC; 9790II, Fuli) for the quantification of $\mathrm{CO}$ and $\mathrm{H}_{2}$. The $\mathrm{GC}$ was equipped with a packed HaySep A column, a packed MolSieve 5 A column, and a packed Porapak N column with argon (Praxair, 99.999\%) as the carrier gas. A thermal conductivity detector (TCD) was used to qualify and quantify $\mathrm{H}_{2}$. A flame ionization detector coupled with a Ni reformer was used to qualify and quantify CO. For the Faradaic efficiency (FE) tests, the product gas was tested in GC after 15 min of the reaction at each set potential.

The product gas was introduced into GC to test the FE of $\mathrm{CO}$ and $\mathrm{H}_{2}$.

The calculation of FE follows Eq. 1:

$\mathrm{FE}=\frac{n F C_{i} v P}{j R T}$

where $n$ is the number of electrons involved; $F$ as the Faradaic constant $\left(96,485.33289 \mathrm{C} \mathrm{mol}^{-1}\right) ; C_{i}$ as the volume fraction of a certain product determined by online GC; $v=20$ $\operatorname{sccm}\left(3.3 \times 10^{-7} \mathrm{~m}^{3} \mathrm{~s}^{-1}\right) ; P=101,300 \mathrm{~Pa} ; j=$ Total current (A); $R$ as the gas constant of $8.314 \mathrm{~J} \mathrm{~mol}^{-1} \mathrm{~K}^{-1} ; T=293 \mathrm{~K}$.
The current densities of $\mathrm{CO}\left(j_{\mathrm{co}}\right)$ and $\mathrm{H}_{2}\left(j_{\mathrm{H} 2}\right)$ are calculated based on Eq. 2:

$j_{\mathrm{co}(H 2)}=j_{\text {total }} \times \mathrm{FE}_{\mathrm{co}(H 2)}$

The total turnover frequency (TOF) for $\mathrm{CO}$ and $\mathrm{H}_{2}$ was calculated by assuming all the active sites were $\mathrm{M}-\mathrm{N}_{4}$ sites and based on Eq. 3:

$\mathrm{TOF}=\frac{j_{\mathrm{co}(H 2)} \times A_{\text {electrode }} / 2 \times 1.6 * 10^{-19}}{M_{\text {sample }} N_{\%} M N_{\%} N_{A} / 4 \times M_{N}}$

where $j_{\mathrm{co}(H 2)}$ is the current density of $\mathrm{CO}\left(j_{\mathrm{co}}\right)$ or $\mathrm{H}_{2}\left(j_{\mathrm{H} 2}\right)$, $A_{\text {electrode }}=1 \mathrm{~cm}^{-2}$ is the electrode geometric area, $M_{\text {sample }}=$ $5 \times 10^{-4} \mathrm{~g}$ is the mass of catalyst on the electrode, $N_{\%}$ is the mass ratio of Nitrogen in the catalyst obtained from XPS, $M N_{\%}$ is the metal-N content ratio obtained from the XPS deconvolution results of $\mathrm{N} 1 \mathrm{~s}, N_{A}=6.02 \times 10^{23}$ is Avogadro constant, $M_{N}$ is the atomic mass of nitrogen.

The Tafel slope was calculated based on the Tafel equation (Eq. 4):

$\eta=a+b \log j_{C O}$

where $\eta$ is the overpotential, $b$ is the Tafel slope, and $j_{C O}$ is the current density for $\mathrm{CO}$ formation.

\section{Results and Discussion}

\subsection{Preparation and Characterization of Catalysts}

The one-pot synthesis strategy of mixing all the ingredients led to a relatively small product yield (which could not be collected). The two-step synthesis method is employed to fabricate the atomically dispersed bimetallic catalysts. The synthetic procedure for the bimetallic $\mathrm{Co}-\mathrm{Fe}$ catalysts is illustrated in Fig. 1a. The Fe-Co-ZIF precursors are prepared with the impregnation method to modify ZIF-8 into Co-ZIF [8] and absorb Fe source (detailed in supporting information). Through this two-step synthesis method, the introduction of $\mathrm{Fe}$ does not interfere with the crystallization of Co-ZIF particles, resulting in the success of the yield of the bimetallic $\mathrm{Fe}-\mathrm{Co}-\mathrm{ZIF}$ precursors. Combined with the pyrolysis process to carbonize the ZIF particles and vaporization of $\mathrm{Zn}$, atomically dispersed $\mathrm{Co}$, Fe bimetallic catalysts are finally fabricated. SEM images reveal that the series of $\mathrm{Fe}-\mathrm{Co}-\mathrm{ZIFs}$ retain the morphology of the original 

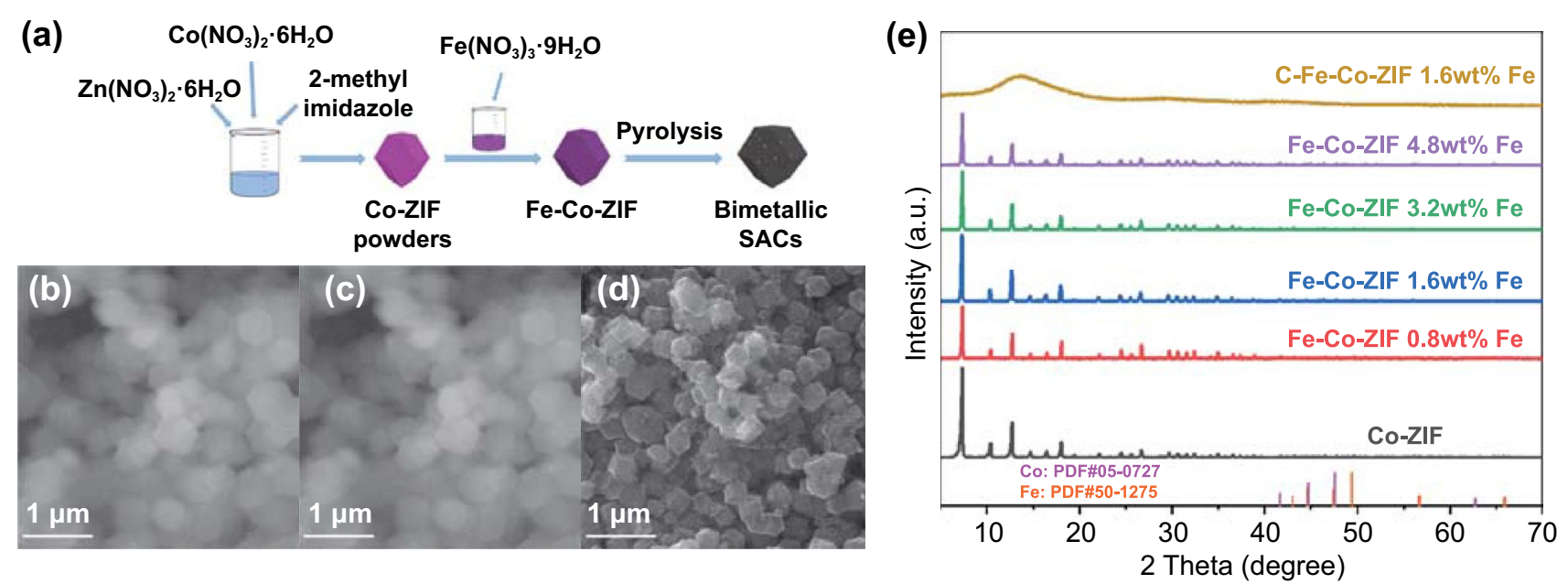

Fig. 1 Structural characterization of C-Fe-Co-ZIF catalysts. a A fabrication schematic of the C-Fe-Co-ZIF catalysts; SEM images of b CoZIF. c Fe-Co-ZIF-1.6 wt\%-Fe. d C-Fe-Co-ZIF-1.6 wt\%-Fe at scale bar of $1 \mu \mathrm{m}$. e XRD patterns of Fe-Co-ZIF series catalysts with different Fe adding amounts and the carbonized Fe-Co-ZIF-1.6 wt\%-Fe (C-Fe-Co-ZIF)

Co-ZIFs with the various amount of Fe added in the synthesis (Figs. 1b, c, and S1). After the pyrolysis process, the carbonized $\mathrm{Fe}-\mathrm{Co}-\mathrm{ZIF}$ (C-Fe-Co-ZIF) catalysts retain the morphology of $\mathrm{Fe}-\mathrm{Co}-\mathrm{ZIFs}$ (Fig. 1c, d). C-Fe-Co-ZIF also has better conductivity than ZIF precursors, providing improved image quality in Fig. 1d than Fig. 1b, c. XRD measurements show that Fe-Co-ZIFs keep the same crystalline structure as that of Co-ZIF, without any characteristic peak assigned to Co and Fe crystals (Fig. 1e). The absence of $\mathrm{Co}$ and $\mathrm{Fe}$ in XRD patterns can be due to the extremely low content of the metal element in the final catalysts (ICP indicates: $2.2 \mathrm{wt} \%$ of $\mathrm{Co}$ and $1.0 \mathrm{wt} \%$ of $\mathrm{Fe}$ in $\mathrm{C}-\mathrm{Fe}-\mathrm{Co}-\mathrm{ZIF}-$ $4.8 \mathrm{wt} \%-\mathrm{Fe}$ ). The XRD pattern of $\mathrm{C}-\mathrm{Fe}-\mathrm{Co}-\mathrm{ZIF}$ (Fig. 1e) demonstrates that the final bimetallic catalysts appear as amorphous carbon material.

TEM images show that the $\mathrm{C}-\mathrm{Fe}-\mathrm{Co}-\mathrm{ZIF}$ particles are around $300 \mathrm{~nm}$ (Fig. 2a-c), which agrees with the SEM results. The energy-dispersive X-ray (EDX) spectroscopy elemental mappings depict the distributions of $\mathrm{Co}, \mathrm{Fe}, \mathrm{C}$, and $\mathrm{N}$, indicating that $\mathrm{Co}$ and $\mathrm{Fe}$ atoms are evenly distributed in C-Fe-Co-ZIF (Fig. 2d). Aberration-corrected high-angle annular dark-field scanning transmission electron microscopy (HAADF-STEM) with the sub-angstrom resolution are employed to directly observe the atomic dispersion of the metal atoms, benefiting from higher Z-contrast of $\mathrm{Co}$ and $\mathrm{Fe}$ than $\mathrm{N}$ and $\mathrm{C}$ (Fig. 2e, f). In Fig. 2f, the single atom of $\mathrm{Co}$ and $\mathrm{Fe}$ (tiny bright spots) are well dispersed in $\mathrm{C}-\mathrm{Fe}-\mathrm{Co}-\mathrm{ZIF} 1.6 \mathrm{wt} \% \mathrm{Fe}$. To further demonstrate so, we have also conducted the X-ray absorption spectroscopy analysis, and indeed, we found the existence of the peaks for single-atom bindings in EXAFS (please see the corresponding discussion later on in this work). In short, the HAADF-TEM and EXAFS results are auxiliary to support the conception of single atoms in the catalysts. Other than atomically dispersed metal atoms, small metal clusters are also found in the bimetallic catalysts (Fig. S2). It illustrates the co-existence of the single-metal-atoms and metal clusters in the $\mathrm{C}-\mathrm{Fe}-\mathrm{Co}-\mathrm{ZIF}$.

Soft X-ray (metal L-edge) is attributed to the excitement of the $3 \mathrm{~d}$ valence states. And the total electron yield mode (TEY) of metal L-edge is a surface-sensitive technique, which could be a more sensitive and direct probe for the metal oxidation states on the surface of the catalyst. The Co L-edge X-ray absorption spectroscopy (XAS) is shown in Fig. 3a. In the region at ca. $795 \mathrm{~V}$, the peaks for $\mathrm{C}-\mathrm{Fe}-\mathrm{Co}-\mathrm{ZIF}$ are located between $\mathrm{Co}$ wire and $\mathrm{Co}\left(\mathrm{NO}_{3}\right)_{2}$. It suggests that the valences of $\mathrm{Co}$ atoms in $\mathrm{C}-\mathrm{Fe}-\mathrm{Co}-\mathrm{ZIF}$ catalysts are between 0 to +2 . There are two main peaks in the region from 778 to $782 \mathrm{~V}$. Co wire $\left(\mathrm{Co}^{0}\right)$ is dominated by the peak located before $780 \mathrm{~V}$, while $\mathrm{Co}\left(\mathrm{NO}_{3}\right)_{2}\left(\mathrm{Co}^{2+}\right)$ is dominated by the peak located after $780 \mathrm{~V}$. All C-Fe-Co-ZIFs have the relatively close intensity for these two peaks while the intensity of the peak after $780 \mathrm{~V}$ is slightly higher than that of the peak before $780 \mathrm{~V}$, indicating the valences for the $\mathrm{C}-\mathrm{Fe}-\mathrm{Co}-\mathrm{ZIF}$ samples are close to +2 . Fe L-edge XAS in Fig. $3 b$ demonstrates that all the $\mathrm{C}-\mathrm{Fe}-\mathrm{Co}-\mathrm{ZIFs}$ samples 

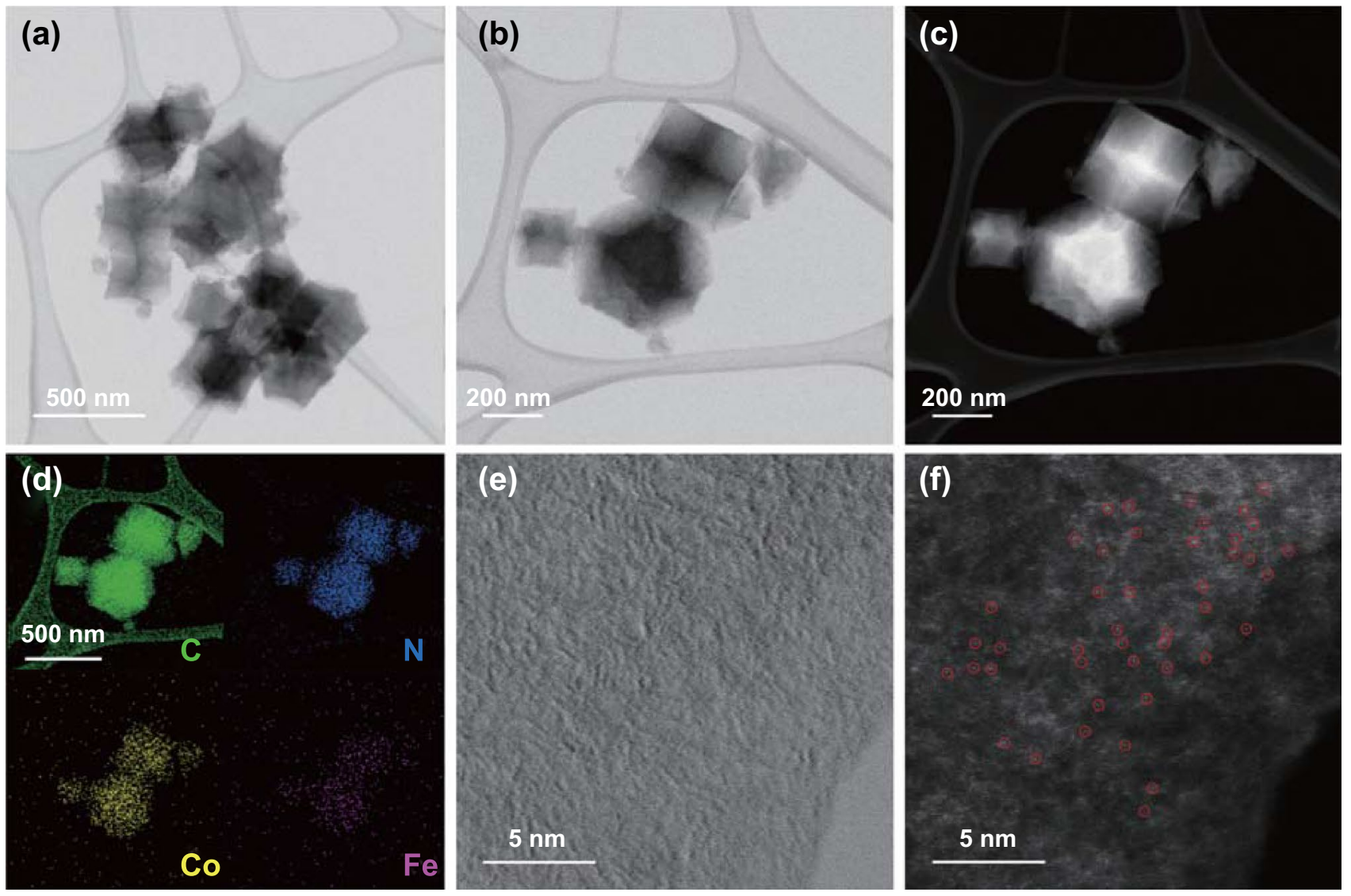

Fig. 2 a, b TEM images, c HAADF-STEM images, $\mathbf{d}$ elemental mapping images, e magnified TEM images, f atomic-resolution HAADFSTEM images of $\mathrm{C}-\mathrm{Fe}-\mathrm{Co}-\mathrm{ZIF}-1.6 \mathrm{wt} \%$-Fe powders

share the same peak pattern. The peak at ca. 707 and $709 \mathrm{eV}$ can be ascribed to $t_{2 \mathrm{~g}}$ and $e_{\mathrm{g}}$ states, respectively [25]. The enlarged region in Fig. 3d indicates that the valences of $\mathrm{Fe}$ atoms in $\mathrm{C}-\mathrm{Fe}-\mathrm{Co}-\mathrm{ZIF}$ catalysts are between 0 to +3 . The results agree well with previous literature that TMs in SACs are usually in an oxidation state [26, 27]. Furthermore, $\mathrm{N}$ sites in the catalysts are investigated from $\mathrm{N}$ K-edge XAS (Fig. 3c). Two absorption edges at around $400 \mathrm{eV}$ and $407 \mathrm{eV}$ are corresponding to $1 s \rightarrow \pi^{*}$ and $1 s \rightarrow \sigma^{*}$ transitions, respectively [28]. The wide peaks at ca. $407 \mathrm{eV}$ show no obvious changes in all samples. In the $1 s \rightarrow \pi^{*}$ edge, the peaks at ca. $401.5 \mathrm{eV}(\mathrm{N} 4)$ appear for all the samples, which can be assigned to graphitic $\mathrm{N}$. Almost all the samples reveal a plateau in the range from 398.5 to $400.5 \mathrm{eV}$, where peaks at ca. $398.8(\mathrm{~N} 1), 399.2(\mathrm{~N} 2)$, and $400.5(\mathrm{~N} 3) \mathrm{eV}$ can be assigned to pyridinic $\mathrm{N}$, metal- $\mathrm{N}$ bindings, and pyrrolic $\mathrm{N}$, respectively $[12,29]$. The graphitic $\mathrm{N}$, pyridinic $\mathrm{N}$, and pyrrolic $\mathrm{N}$ sometimes could facilitate the $\mathrm{ECO}_{2} \mathrm{RR}$ process but are regarded as less effective than the metal-centered sites $[11,30]$. The contents of metal-N binding directly reflect the property of M-Nx active sites in SACs, which are vital to catalytic reactions such as $\mathrm{ECO}_{2} \mathrm{RR}$ [31-33]. C-Fe-Co-ZIF$1.6 \mathrm{wt} \%-\mathrm{Fe}$ possesses the sharpest peak in the N2 region, which represents the optimal metal-N bindings. It implies the higher metal-N content of C-Fe-Co-ZIF-1.6 wt $\%$-Fe than other samples.

XPS could characterize the specific species on the surface of the material. Although it is challenging to accurately identify the species solely by a single XPS, the combination of the two auxiliary techniques (e.g., XPS and XAS) can strongly support one opinion. Thus, we further verified the N K-edge results from XAS, by XPS. The XPS of $\mathrm{N} 1 \mathrm{~s}$ in Fig. 4a-e confirms the ascription of pyridinic N, metal-N, pyrrolic N, and graphitic N. Notably, The percentage comparison of metal- $\mathrm{N}$ content among all the $\mathrm{N}$ species for $\mathrm{C}-\mathrm{Fe}-\mathrm{Co}-\mathrm{ZIF}$ in Fig. 4f shows that the metal-N 
(a)

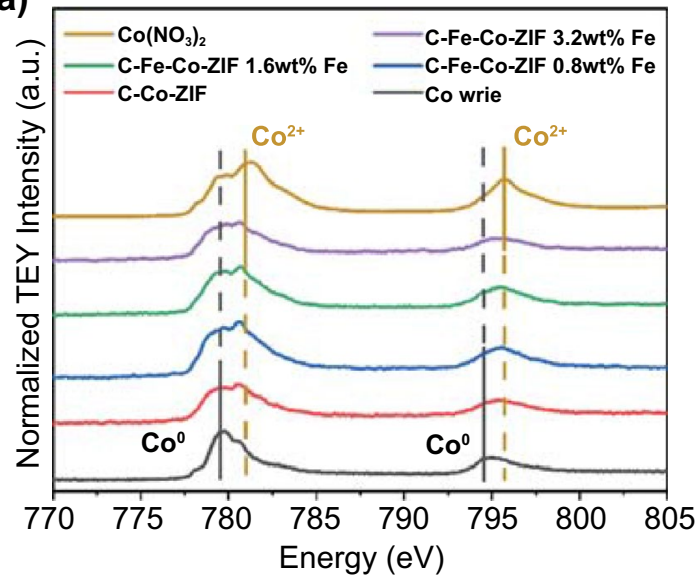

(c)

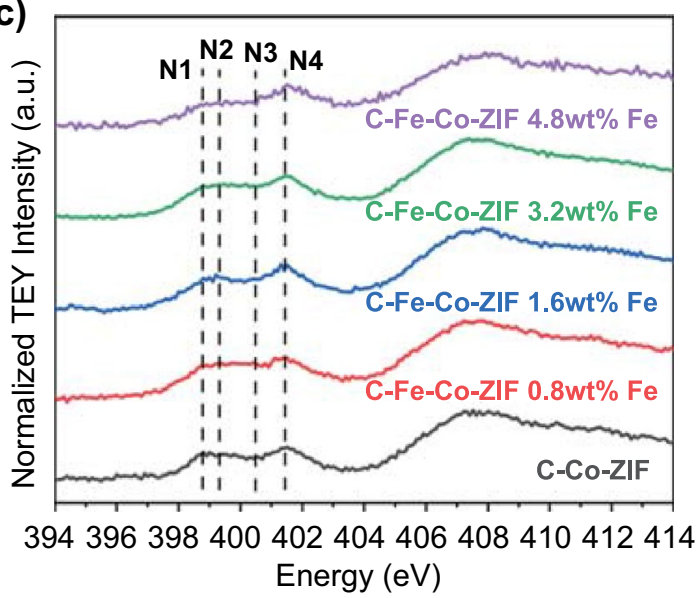

(b)

(d)
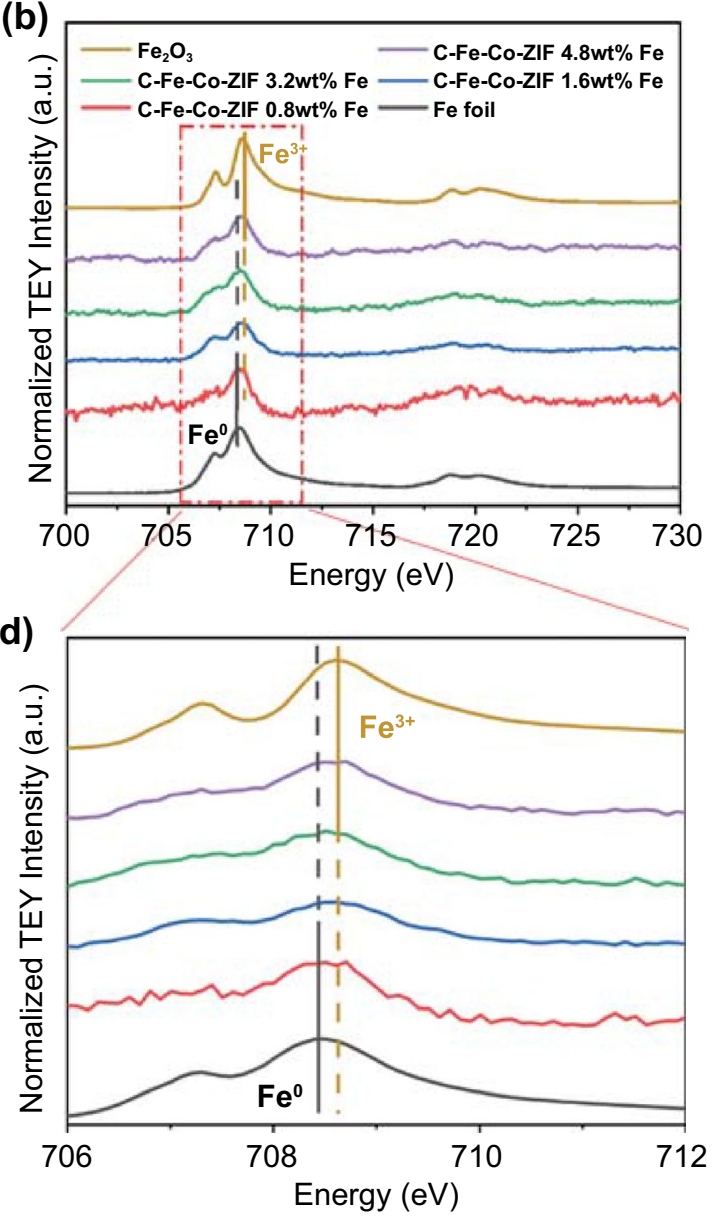

Fig. 3 a Co L-edge XAS. b Fe L-edge XAS. c N K-edge XAS. d Enlarged Fe L-edge XAS of C-Fe-Co-ZIF samples

content increases significantly for C-Fe-Co-ZIF-1.6 wt\%$\mathrm{Fe}$, which is consistent with the XAS results. It suggests that $\mathrm{C}-\mathrm{Fe}-\mathrm{Co}-\mathrm{ZIF}-1.6 \mathrm{wt} \%$-Fe could contain the maximum active sites for $\mathrm{ECO}_{2} \mathrm{RR}$. As the Fe content continuously increases in the catalyst precursor, however, the metal-N content decreases in the $\mathrm{C}-\mathrm{Fe}-\mathrm{Co}-\mathrm{ZIF}$. It is possibly due to the generation of the metal clusters when too much $\mathrm{Fe}$ is added, that the aggregation hinders the formation of metal$\mathrm{N}$ bindings.

Hard X-ray (metal K-edge) that is bulk sensitive could not only provide information (XANES) on the metal oxidation states but also give insights into the local coordination environments (from EXAFS), which is essential for the SAC characterization. XANES of Co in Fig. 5a further reveals that gradually increasing the introduction of Fe reduces the valence of Co in the catalysts (shift to the low energy side). The valences of $\mathrm{Co}$ atoms in $\mathrm{C}-\mathrm{Fe}-\mathrm{Co}-\mathrm{ZIF}-0.8 \mathrm{wt} \%$-Fe and
$1.6 \mathrm{wt} \%$-Fe are the closest to that of C-Co-ZIF. In addition, the pre-edge structure at ca. $7711 \mathrm{eV}$ increases with the increase in $\mathrm{Fe}$ in the samples. This pre-edge peak belongs to the quadrupole electron transition of Co $1 \mathrm{~s}$ to Co $3 \mathrm{~d}$, which reflects the density of empty Co $3 \mathrm{~d}$ orbitals via hybridization [34]. For C-Fe-Co-ZIF-4.8 wt\%-Fe, the pre-edge peak shifts toward that of the Co foil. During the synthesis, only a small amount of $\mathrm{Fe}$ is added into Co-ZIF. It is not likely that Co particles are formed because of the increasing metal content of $\mathrm{Fe}$ in the final catalyst. Thus, the increased intensity of the pre-edge peak indicates that the adding of Fe affects the electronic structure of Co. The XANES pattern tends to be close to that of Co foil when the $\mathrm{Fe}$ content is increased. It implies that Co elements are gradually turning into metallic states with the addition of Fe.

EXAFS is conducted to investigate the coordination environment of Co sites. As shown in Fig. 5b, the C-Co-ZIF 
(a)

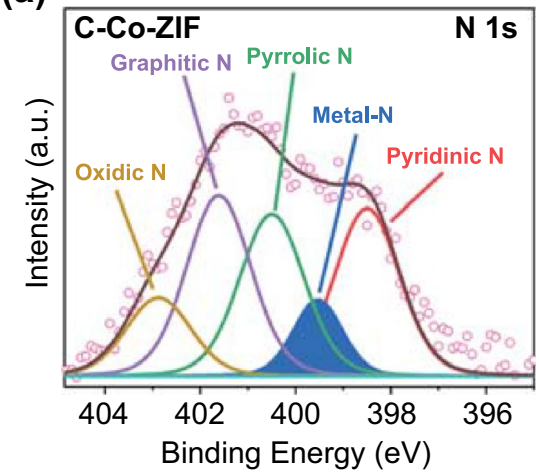

(d)

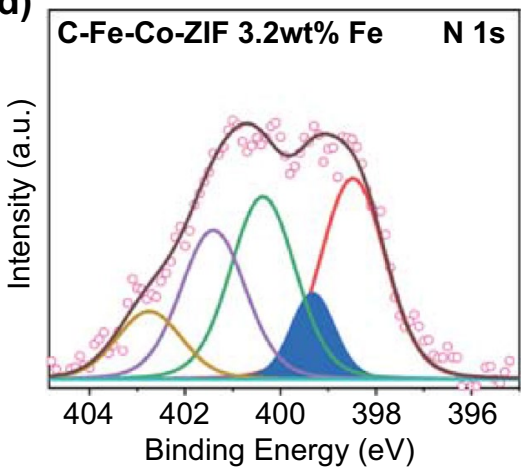

(b)

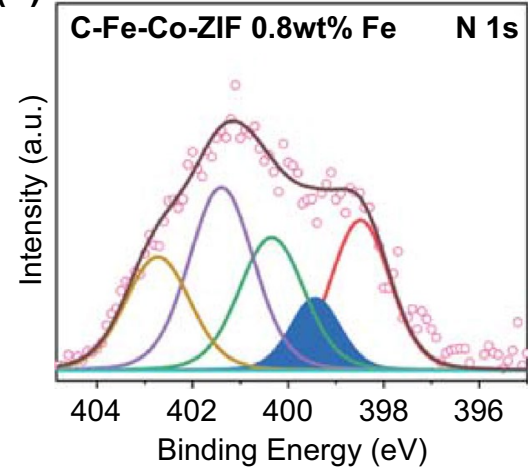

(e)

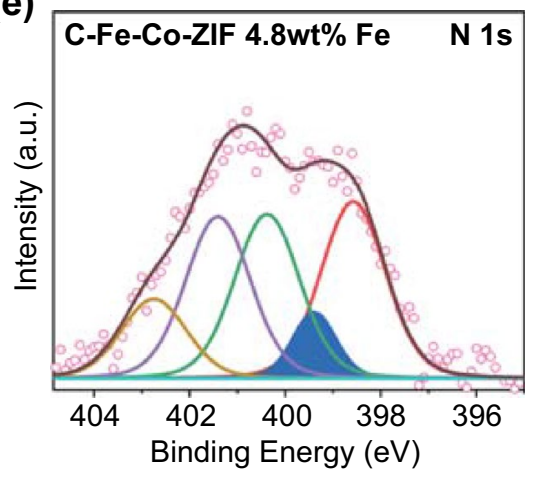

(c)

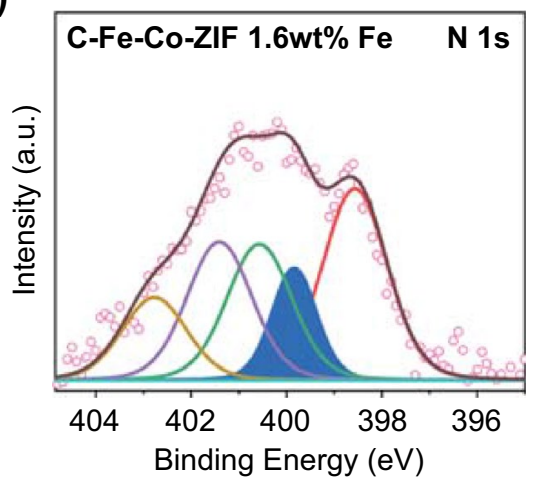

(f)

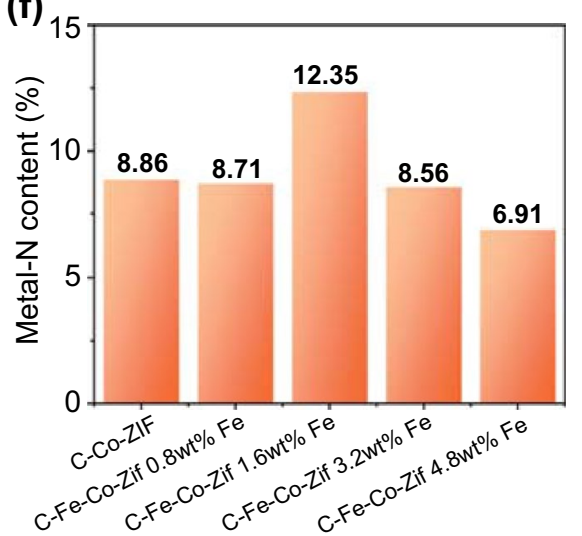

Fig. 4 N 1 s XPS of a C-Co-ZIF, b C-Fe-Co-ZIF-0.8 wt\%-Fe, c C-Fe-Co-ZIF-1.6 wt\%-Fe, d C-Fe-Co-ZIF-3.2 wt\%-Fe, e C-Fe-Co-ZIF$4.8 \mathrm{wt} \%-\mathrm{Fe}$. $\mathbf{f}$ The percentage of metal-N content among $\mathrm{N}$ species of $\mathrm{C}-\mathrm{Fe}-\mathrm{Co}-\mathrm{ZIF}$ samples

sample exhibits a prominent peak at ca. $1.6 \AA$, which can be ascribed to the $\mathrm{Co}-\mathrm{N}, \mathrm{Co}-\mathrm{O}$, and $\mathrm{Co}-\mathrm{C}$ coordination, indicating the single-atom state of Co atoms. Several previous studies confirm that metal-N bonds dominate similarly as the peak in ZIF-8 derived SACs [8, 33, 35]. Combined with the XPS results, this peak could be plausibly assigned to Co-N bindings. The peak at ca. $2.1 \AA$ is close to the main peak of Co foil (Fig. S3), which can be ascribed to metal-metal bindings, i.e., the $\mathrm{Co}-\mathrm{Co}$ coordination. It indicates that $\mathrm{C}-\mathrm{Co}-\mathrm{ZIF}$ consists of atomically dispersed Co atoms as well as Co clusters, which agrees with the TEM results. With a relatively small amount of Fe, the EXAFS $R$ space of $\mathrm{C}-\mathrm{Fe}-\mathrm{Co}-\mathrm{ZIF}-0.8 \mathrm{wt} \%-\mathrm{Fe}$ shows a dramatic decrease in peak intensities, implying either the significant decrease in coordination number or the intense distortion of the coordination environment of $\mathrm{Co}$ atoms. The main peaks of C-Fe-Co-ZIF-0.8 wt\%-Fe are located at ca. $1.5 \AA$ and ca. $2.3 \AA$, which is not identical to that of C-Co-ZIF. It suggests that the $\mathrm{Fe}$ atoms greatly affect the coordination environment of Co sites in C-Fe-Co-ZIF-0.8 wt\%-Fe. With the increase in Fe content, the $R$ space peaks of C-Fe-Co-ZIF$1.6 \mathrm{wt} \%-\mathrm{Fe}$ tend to be similar to those of C-Co-ZIF with different intensities of the main peaks. It indicates that in the $\mathrm{C}-\mathrm{Fe}-\mathrm{Co}-\mathrm{ZIF}-1.6 \mathrm{wt} \%-\mathrm{Fe}$, the coordination environment of Co sites is less affected by the introduction of $\mathrm{Fe}$ than that of $\mathrm{C}-\mathrm{Fe}-\mathrm{Co}-\mathrm{ZIF}-0.8 \mathrm{wt} \%-\mathrm{Fe}$. With large content of $\mathrm{Fe}, \mathrm{C}-\mathrm{Fe}-\mathrm{Co}-\mathrm{ZIF}-4.8 \mathrm{wt} \%$-Fe exhibits a prominent peak at ca. $2.1 \AA$ that belongs to metal-metal bindings, ascribed to $\mathrm{Co}-\mathrm{Fe}$ or $\mathrm{Fe}-\mathrm{Fe}$ coordination. It implies that the large amount of Fe could greatly affect the coordination environment of Co sites (C-Fe-Co-ZIF-4.8 wt\%-Fe).

The above methodology is applied for the analysis of $\mathrm{Fe}$ atoms. XANES of Fe in Fig. 5c reveals that the gradually increased amount of $\mathrm{Fe}$ reduces the valence of $\mathrm{Fe}$ in the catalysts, while the valences of $\mathrm{Fe}$ in $\mathrm{C}-\mathrm{Fe}-\mathrm{Co}-\mathrm{ZIF}$ $0.8 \mathrm{wt} \%-\mathrm{Fe}$ and $\mathrm{C}-\mathrm{Co}-\mathrm{ZIF}-1.6 \mathrm{wt} \%$-Fe are similar. The near edge structure at ca. $7115 \mathrm{eV}$ is assigned to $1 \mathrm{~s}$ to $3 \mathrm{~d}$ transitions [36]. With the increasing adding amount of Fe, the XANES tends to become similar to that of $\mathrm{Fe}$ foil, implying the agglomeration of Fe atoms. The 
(a)

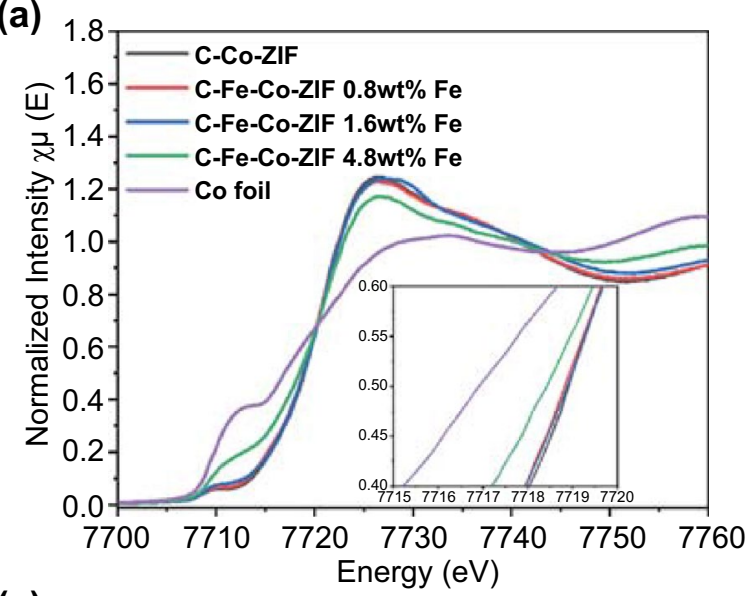

(c)

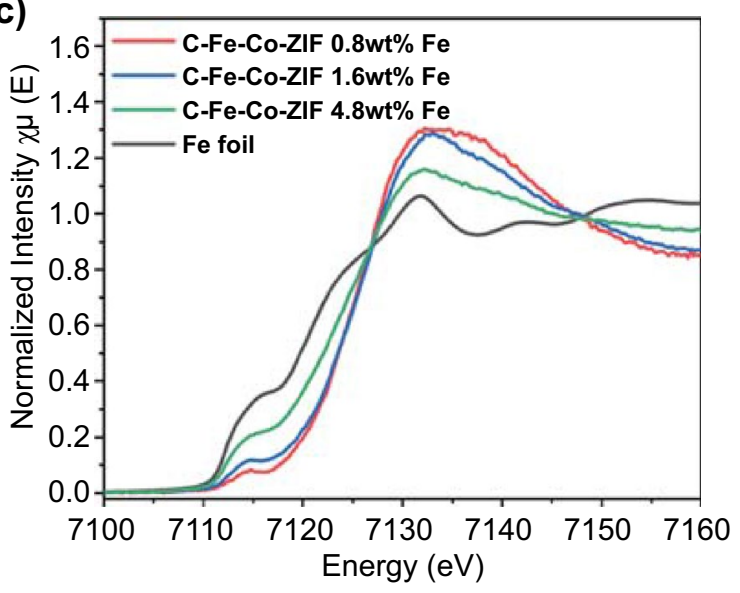

(b)

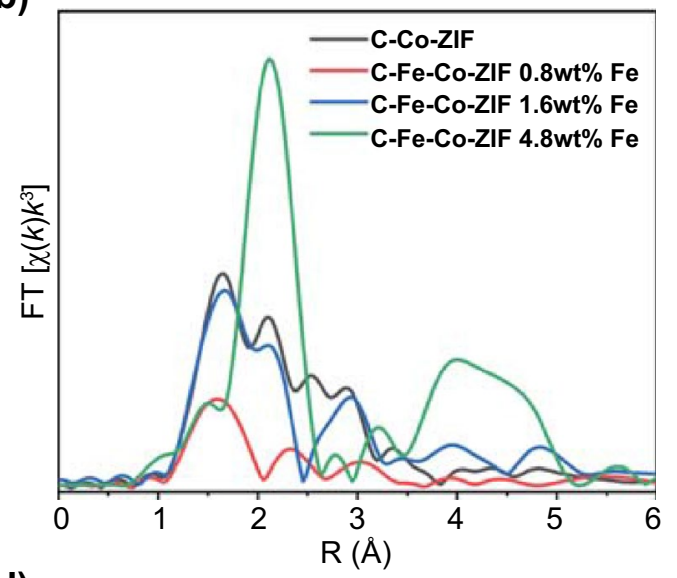

(d)

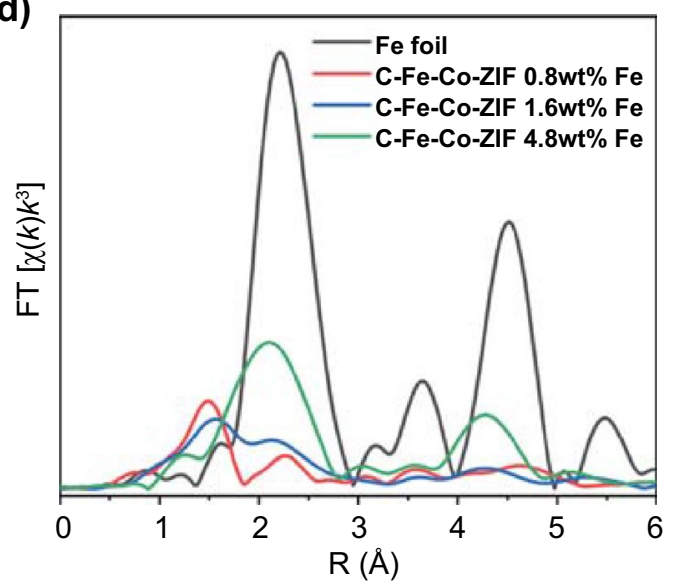

Fig. 5 a Co K-edge XANES, inset: enlarged region of the white line. b Co EXAFS. c Fe K-edge XANES. d Fe EXAFS of C-Fe-Co-ZIF samples

coordination environment of Fe sites is investigated by EXAFS (Fig. 5d). The prominent peak at ca. $1.5 \AA$ of $\mathrm{C}-\mathrm{Fe}-\mathrm{Co}-\mathrm{ZIF}-0.8 \mathrm{wt} \%-\mathrm{Fe}$ is ascribed to $\mathrm{Fe}-\mathrm{N}$ bindings (similar interpretation as $\mathrm{Co}-\mathrm{N}$ ), indicating the dominant single-metal-atom state of $\mathrm{Fe}$ atoms. With the increasing amount of $\mathrm{Fe}$, the dominant $\mathrm{Fe}-\mathrm{N}$ peak for C-Fe-Co-ZIF-1.6 wt\%-Fe shifts a little to ca. $1.6 \AA$ with a decreased intensity, indicating the distortion to the coordination environment of $\mathrm{Fe}-\mathrm{N}$ in the catalyst. The peaks at ca. $2.1 \AA$ are observed for C-Fe-Co-ZIF-1.6 wt $\%$-Fe and $\mathrm{C}-\mathrm{Fe}-\mathrm{Co}-\mathrm{ZIF}-4.8 \mathrm{wt} \%-\mathrm{Fe}$. This peak location is not identical to the $\mathrm{Fe}-\mathrm{Fe}$ binding of $\mathrm{Fe}$ foil $(2.2 \AA)$ but the same as the one in the previous Co $R$ space analysis (Fig. 5b), supporting the assumption of the $\mathrm{Co}-\mathrm{Fe}$ coordination in the $\mathrm{Fe}-\mathrm{Co}$ bimetallic catalyst samples.

\subsection{Catalytic Performance of the C-Fe-Co-ZIFs for $\mathrm{ECO}_{2} \mathrm{RR}$}

The $\mathrm{ECO}_{2} \mathrm{RR}$ evaluations are performed in a custom-made $\mathrm{H}$-cell. Several cycles of CV are pre-run before the electrochemical measurements to stabilize the catalyst electrode. Both $\mathrm{CV}$ curves in $\mathrm{N}_{2}$ and $\mathrm{CO}_{2}$ atmospheres for different $\mathrm{C}-\mathrm{Fe}-\mathrm{Co}-\mathrm{ZIF}$ catalysts are measured (Fig. S4). LSV curves of $\mathrm{C}-\mathrm{Fe}-\mathrm{Co}-\mathrm{ZIF}-1.6 \mathrm{wt} \%-\mathrm{Fe}$ are better than those of the pure $\mathrm{C}-\mathrm{Co}-\mathrm{ZIF}$, in both $\mathrm{N}_{2}$ and $\mathrm{CO}_{2}$ atmospheres (Figs. 6a and S4). Compared to the LSV curve in $\mathrm{N}_{2}$, C-Fe-Co-ZIF-1.6 wt\%-Fe shows an enhanced current response in the $\mathrm{CO}_{2}$ atmosphere in the range of around -0.35 to $-0.65 \mathrm{~V}$ versus RHE. The crossing of $\mathrm{CV}$ curves in $\mathrm{N}_{2}$ and $\mathrm{CO}_{2}$ indicates the production rates of 
(a)

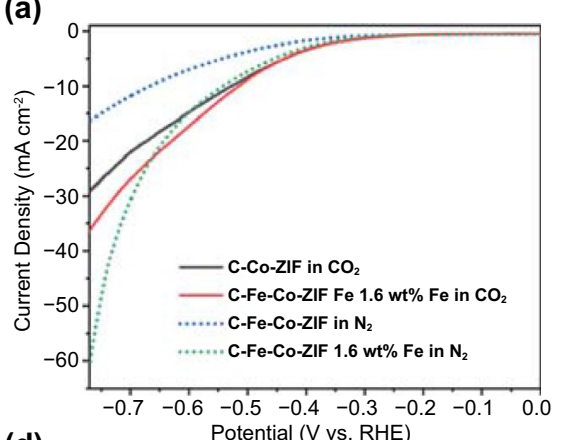

(d)

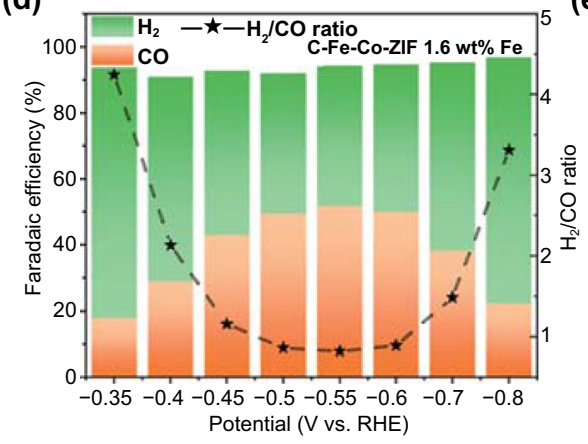

(b)

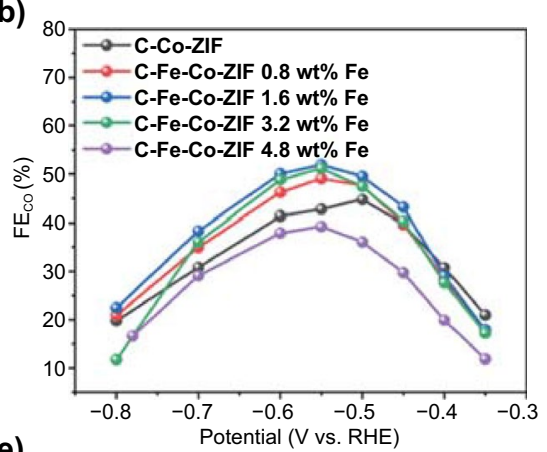

(e)

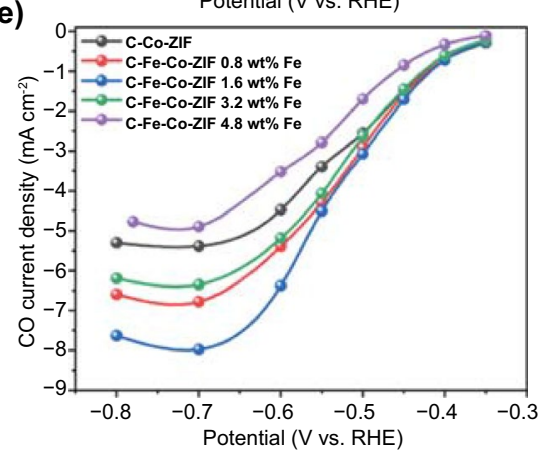

(c)

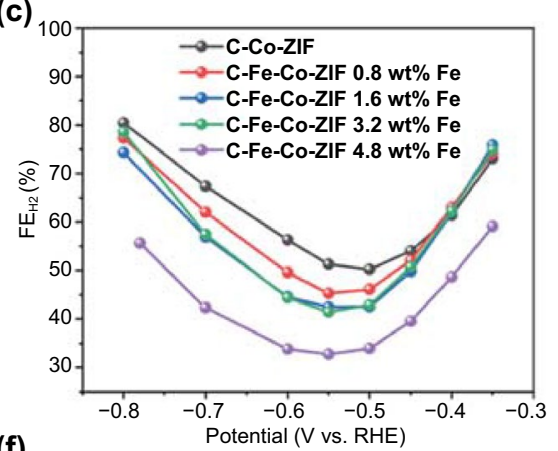

(f)

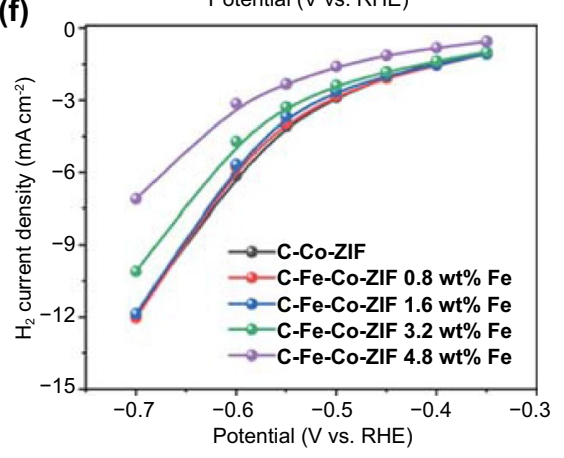

Fig. 6 Evaluation of the electrocatalytic performance of the samples. a LSV curves of C-Co-ZIF and C-Fe-Co-ZIF-1.6 wt\%-Fe in $\mathrm{N}_{2}$ or $\mathrm{CO}_{2}$-saturated $0.5 \mathrm{M} \mathrm{KHCO}_{3}$ solution at a scan rate of $5 \mathrm{mV} \mathrm{s}^{-1}$. b CO Faradaic efficiency of the catalysts at various applied potentials. c $\mathrm{H}_{2}$ Faradaic efficiency of the catalysts at various applied potentials. d Bars: $\mathrm{FE}_{\mathrm{CO}}$ and $\mathrm{FE}_{\mathrm{H} 2}$; Stars: $\mathrm{H}_{2} / \mathrm{CO}$ ratio of C-Fe-Co-ZIF-1.6 wt\%-Fe at various applied potentials. e $\mathrm{CO}$ current density of the catalysts. $\mathbf{f} \mathrm{H}_{2}$ current density of the catalysts

$\mathrm{CO}$ and $\mathrm{H}_{2}$ are dependent, implying the tunable ratio of $\mathrm{CO} / \mathrm{H}_{2}$ by adjusting the potential.

FE results in Fig. 6b, c reveal that $\mathrm{FE}_{\mathrm{CO}}$ and $\mathrm{FE}_{\mathrm{H} 2}$ are in the opposite trend for all the catalysts. $\mathrm{C}-\mathrm{Fe}-\mathrm{Co}-\mathrm{ZIF}-0.8$ wt\%-Fe, C-Fe-Co-ZIF-1.6 wt\%-Fe, and C-Fe-Co-ZIF$3.2 \mathrm{wt} \%-\mathrm{Fe}$ exhibit higher $\mathrm{FE}_{\mathrm{CO}}$ and lower $\mathrm{FE}_{\mathrm{H} 2}$, compared to those of $\mathrm{C}-\mathrm{Co}-\mathrm{ZIF}$, indicating the promoted $\mathrm{CO}$ production in the $\mathrm{Co}, \mathrm{Fe}$ bimetallic catalyst during the $\mathrm{ECO}_{2} \mathrm{RR}$ process. C-Fe-Co-ZIF-1.6 wt $\%-\mathrm{Fe}$ and $\mathrm{C}-\mathrm{Fe}-\mathrm{Co}-\mathrm{ZIF}-3.2 \mathrm{wt} \%$-Fe have similar $\mathrm{FE}_{\mathrm{CO}}$ and $\mathrm{FE}_{\mathrm{H} 2}$, with $\mathrm{FE}_{\mathrm{CO}}$ of around $52 \%$ (about $10 \%$ higher than that of pure $\mathrm{C}-\mathrm{Co}-\mathrm{ZIF}$ ) and $\mathrm{FE}_{\mathrm{H} 2}$ around $42 \%$ at $-0.55 \mathrm{~V}$ versus RHE. The ratio of $\mathrm{H}_{2} / \mathrm{CO}$ can be tuned from 0.8 to 4.2 at different potentials while maintaining the total $\mathrm{FE}_{\mathrm{CO}+\mathrm{H} 2}$ above $90 \%$ (Fig. 6d). Most of the $\mathrm{C}-\mathrm{Fe}-\mathrm{Co}-\mathrm{ZIFs}$ exhibit a higher $\mathrm{CO}$ current than that of $\mathrm{C}-\mathrm{Co}-\mathrm{ZIF}$. $\mathrm{C}-\mathrm{Fe}-\mathrm{Co}-\mathrm{ZIF}-1.6 \mathrm{wt} \%$-Fe has the highest $\mathrm{CO}$ current density of $8.0 \mathrm{~mA} \mathrm{~cm}^{-2}$ at $-0.7 \mathrm{~V}$ versus RHE (Fig. 6e). Negligible $\mathrm{CO}$ is detected under the controlled electrochemical experiments (in $\mathrm{N}_{2}$ atmosphere), confirming the direct $\mathrm{CO}$ production from the gaseous $\mathrm{CO}_{2}$ during
$\mathrm{ECO}_{2} \mathrm{RR}$. The $\mathrm{H}_{2}$ current densities of $\mathrm{C}-\mathrm{Fe}-\mathrm{Co}-\mathrm{ZIF}-0.8$ $\mathrm{wt} \%$-Fe and $\mathrm{C}-\mathrm{Fe}-\mathrm{Co}-\mathrm{ZIF}-1.6 \mathrm{wt} \%-\mathrm{Fe}$ are very close to that of C-Co-ZIF while C-Fe-Co-ZIF-3.2 wt\%-Fe and C-Fe-Co-ZIF-4.8 wt\%-Fe exhibit decreased $\mathrm{H}_{2}$ current densities (Fig. 6f). Notably, C-Fe-Co-ZIF-4.8 wt\%-Fe shows decreases in the production activity in both $\mathrm{CO}$ and $\mathrm{H}_{2}$ with a total $\mathrm{FE}_{\mathrm{CO}+\mathrm{H} 2}$ of around only $70 \%$ (Fig. S5), implying the more adding amount of Fe possibly leads to other product formations instead of $\mathrm{CO}$ and $\mathrm{H}_{2}$.

The chronoamperometry of C-Fe-Co-ZIF-1.6 wt\%-Fe in Fig. 7 a shows that, during the $10 \mathrm{~h}$ of reaction, the total current density drops quickly (10\% drop) in the first hour. Then, the decay of the current density is relatively stable, with the maintenance of over $85 \%$ of the initial current density for $9 \mathrm{~h}$. The explosion of the gas bubbles generated on the catalyst electrode during the reaction could cause the cliffs in the current curve. FE of $\mathrm{CO}$ remains stable for more than $10 \mathrm{~h}$ at $52-53 \%$ as well as the $\mathrm{FE}$ of $\mathrm{H}_{2}$ at around $40 \%$ (Fig. $7 b$ ), which is better than several hours presented in many published reports [23, 37-39]. 
(a)
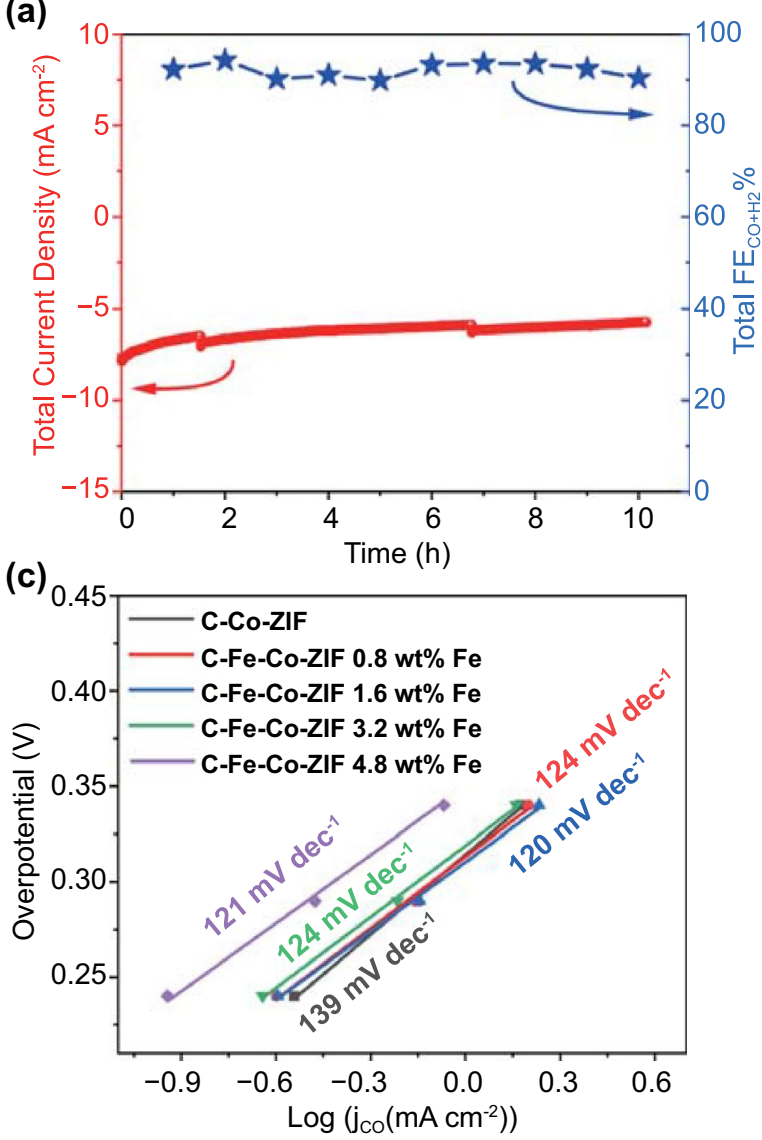

(b)

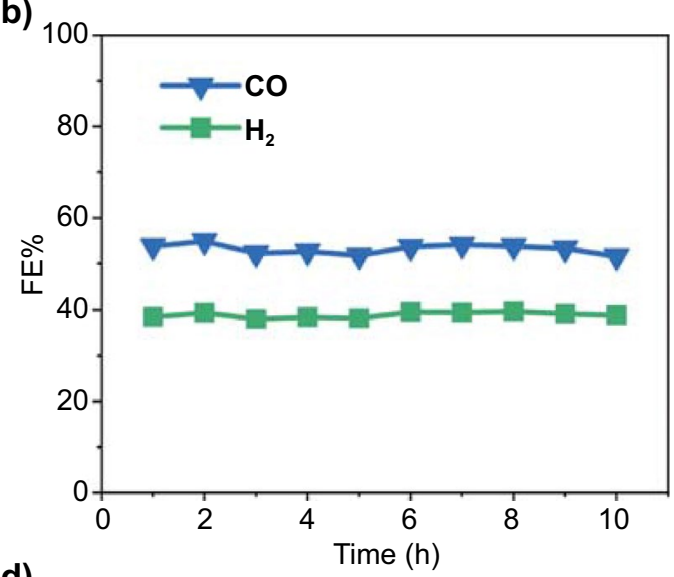

(d)

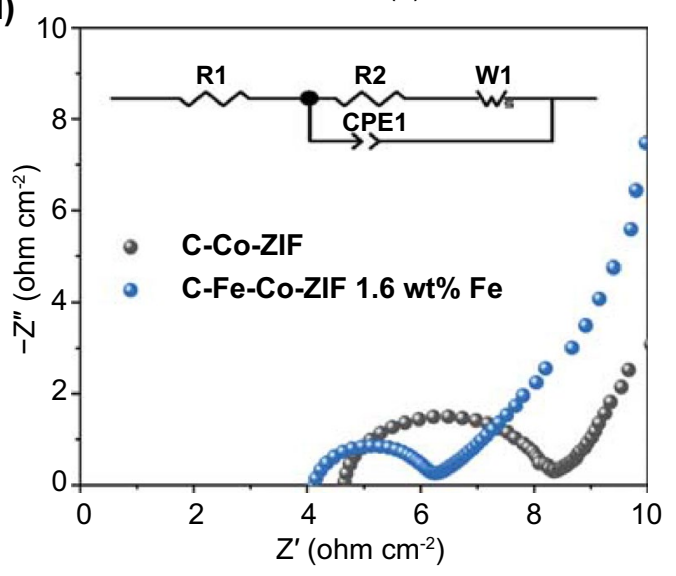

Fig. 7 Chronoamperometry test of a Total current density and total $\mathrm{FE}_{\mathrm{CO}+\mathrm{H} 2}$, b $\mathrm{FE}_{\mathrm{CO}}$ and $\mathrm{FE}_{\mathrm{H} 2}$ of $\mathrm{C}-\mathrm{Fe}-\mathrm{Co}-\mathrm{ZIF}-1.6 \mathrm{wt} \%$-Fe at $-0.55 \mathrm{~V}$ versus RHE under $\mathrm{CO}_{2}$ atmosphere for the stability evaluation. $\mathbf{c}$ Tafel slopes of C-Fe-Co-ZIF catalyst electrodes with different Fe adding amounts. d EIS results of C-Co-ZIF and C-Fe-Co-ZIF-1.6 wt\%-Fe

\subsection{Mechanism Investigation}

$\mathrm{C}-\mathrm{Fe}-\mathrm{Co}-\mathrm{ZIF}-1.6 \mathrm{wt} \%$-Fe has the best $\mathrm{CO}$ production activity of $\mathrm{ECO}_{2} \mathrm{RR}$. We compare the Tafel slope values to gain insights into the $\mathrm{CO}$ formation during $\mathrm{ECO}_{2} \mathrm{RR}$. The schematic of bimetallic Fe-Co catalysts for $\mathrm{ECO}_{2} \mathrm{RR}$ is illustrated in Fig. 8. Tafel slopes of C-Fe-Co-ZIF catalysts are similar in Fig. 7c, of around $120 \mathrm{mV} \mathrm{dec}^{-1}$, which is close to the theoretical value of $118 \mathrm{mV} \mathrm{dec}^{-1}$ for the first electron-transfer step, suggesting the first electron-transfer step $\left(\mathrm{CO}_{2}+\mathrm{e}^{-} \rightarrow \mathrm{CO}_{2}^{*-}\right.$ or $\mathrm{CO}_{2}+\mathrm{e}^{-}+\mathrm{H}^{+} \rightarrow{ }^{*} \mathrm{COOH}$ ) could be the rate-decided step [12]. Compared to the original $\mathrm{C}-\mathrm{Co}-\mathrm{ZIF}$ has a value of $139 \mathrm{mV} \mathrm{dec}^{-1}$ (much higher than that of $\mathrm{C}-\mathrm{Fe}-\mathrm{Co}-\mathrm{ZIF}$ catalysts, Fig. S6), the improvement of the $\mathrm{CO}$ production in $\mathrm{ECO}_{2} \mathrm{RR}$ is caused by the adding of $\mathrm{Fe}$ for $\mathrm{C}-\mathrm{Fe}-\mathrm{Co}-\mathrm{ZIF}$ catalysts. The more positive initial point of the Tafel slope represents the higher current density. With the more adding amount of Fe in the catalyst (C-Fe-Co-ZIF-4.8 wt\%-Fe), the initial point of the Tafel slope shifts significantly toward a negative value, indicating decreased production rate of $\mathrm{CO}$. The double-layer capacitance is employed to estimate the electrochemically active surface area (ECSA) of different catalyst electrodes (Fig. S7). Except for C-Fe-Co-ZIF-4.8 wt\%-Fe that has a decreased ECSA, all the other $\mathrm{C}-\mathrm{Fe}-\mathrm{Co}-\mathrm{ZIF}$ possess similar ECSA as C-Co-ZIF, implying the enhancement of the $\mathrm{CO}$ production for $\mathrm{C}-\mathrm{Fe}-\mathrm{Co}-\mathrm{ZIF}$ catalysts comes from the intrinsic properties of the bimetallic catalysts. TOF of the catalysts is calculated based on Eq. 3, as shown in Table 1. At - $0.7 \mathrm{~V}$ versus RHE, C-Fe-Co-ZIF catalysts show higher $\mathrm{TOF}_{\mathrm{CO}}$ values than that of $\mathrm{C}-\mathrm{Co}-\mathrm{ZIF}$, which agrees with the Tafel slope results. In the meantime, $\mathrm{C}-\mathrm{Fe}-\mathrm{Co}-\mathrm{ZIF}-0.8 \mathrm{wt} \%$ Fe has the highest $\mathrm{TOF}_{\mathrm{CO}}$ and $\mathrm{TOF}_{\mathrm{H} 2}$ values among all the catalysts, indicating the strong interaction between $\mathrm{Fe}$ and $\mathrm{Co}$ 


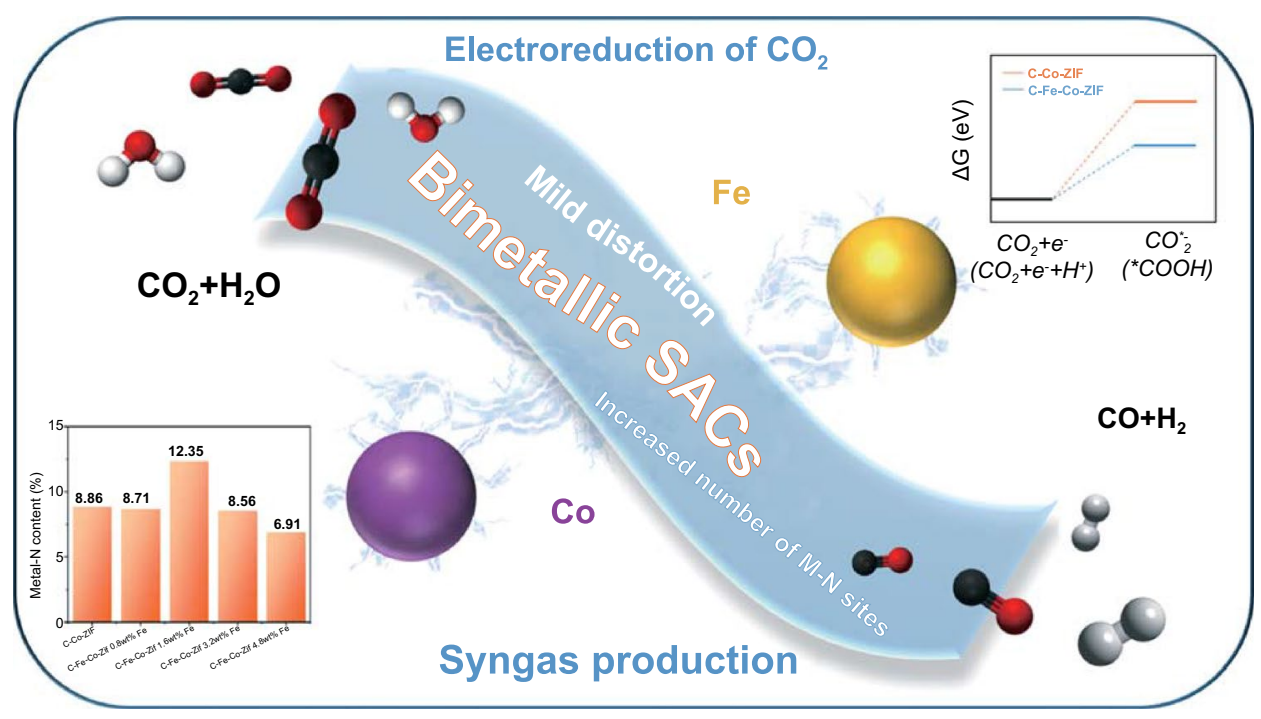

Fig. 8 Schematic reaction mechanism of bimetallic catalysts for $\mathrm{ECO}_{2} \mathrm{RR}$

Table 1 TOF of the catalysts at $-0.7 \mathrm{~V}$ versus RHE

\begin{tabular}{lllll}
\hline & C-Co-ZIF & $\begin{array}{l}\text { C-Fe-Co- } \\
\text { ZIF-0.8 } \\
\text { wt\%-Fe }\end{array}$ & $\begin{array}{l}\text { C-Fe-Co- } \\
\text { ZIF-1.6 } \\
\text { wt\%-Fe }\end{array}$ & $\begin{array}{l}\text { C-Fe-Co- } \\
\text { ZIF-3.2 } \\
\text { wt\%-Fe }\end{array}$ \\
\hline $\begin{array}{l}\mathrm{TOF}_{\mathrm{CO}} \\
\left(\mathrm{site}^{-1} \mathrm{~s}^{-1}\right)\end{array}$ & 0.91 & 1.3 & 1.2 & 1.1 \\
$\mathrm{TOF}_{\mathrm{H} 2}$ & 2.0 & 2.3 & 1.8 & 1.8 \\
$\left(\mathrm{site}^{-1} \mathrm{~s}^{-1}\right)$ & & & & \\
\hline
\end{tabular}

atoms (see the previous discussion of XAS) in the catalysts can promote the $\mathrm{CO}$ and $\mathrm{H}_{2}$ productions during $\mathrm{ECO}_{2} \mathrm{RR}$.

Consistently to all characterizations, $\mathrm{C}-\mathrm{Fe}-\mathrm{Co}-\mathrm{ZIF}-1.6$ wt\%-Fe exhibits both increased $\mathrm{M}-\mathrm{N}$ sites and mild distortions in coordination environments of $\mathrm{Co}-\mathrm{N}$ and $\mathrm{Fe}-\mathrm{N}$, leading to the optimum $\mathrm{ECO}_{2} \mathrm{RR}$ performance. The electrochemical impedance spectroscopy (EIS, Figs. 7d and S8) reveals that C-Fe-Co-ZIF-1.6 wt\%-Fe exhibits an almost 2 times lower charge-transfer resistance than that of $\mathrm{C}-\mathrm{Co}-\mathrm{ZIF}$ (2.085 and $3.691 \Omega$ for C-Fe-Co-ZIF-1.6 wt\%-Fe and C-Co-ZIF, respectively, Fig. S8 and Table S1). The facilitated $\mathrm{CO}_{2}$ activation, increased number of $\mathrm{M}-\mathrm{N}$ sites, and high charge transfer rate attribute to the improved $\mathrm{ECO}_{2} \mathrm{RR}$ performance for Fe-Co-ZIF catalysts (Fig. 8).

\subsection{Applications of $\mathrm{C}-\mathrm{Cu}-\mathrm{Co}-\mathrm{ZIFs}$ and $\mathrm{C}-\mathrm{Ni}-\mathrm{Co}-$ ZIFs for $\mathrm{ECO}_{2} \mathrm{RR}$}

A series of $\mathrm{Cu}-\mathrm{Co}$ and $\mathrm{Ni}-\mathrm{Co}$ bimetallic catalysts based on the same strategy of $\mathrm{C}-\mathrm{Fe}-\mathrm{Co}-\mathrm{ZIFs}$ are synthesized to verify the versatility of atomically dispersed bimetallic method of TM elements in $\mathrm{ECO}_{2} \mathrm{RR}$. The $\mathrm{Cu}-\mathrm{Co}-\mathrm{ZIFs} /$ carbonized $\mathrm{Cu}-\mathrm{Co}-\mathrm{ZIF}(\mathrm{C}-\mathrm{Cu}-\mathrm{Co}-\mathrm{ZIF})$ and $\mathrm{Ni}-\mathrm{Co}-\mathrm{ZIFs} /$ carbonized Ni-Co-ZIF (C-Cu-Co-ZIF) have the same morphology and crystalline structure as that of $\mathrm{Fe}-\mathrm{Co}-\mathrm{ZIF} / \mathrm{C}-\mathrm{Fe}-\mathrm{Co}-\mathrm{ZIF}$ (Figs. S9 and S10). The interactions between $\mathrm{Cu}$ and $\mathrm{Co}$ or $\mathrm{Ni}$ and $\mathrm{Co}$ are confirmed by XANES and EXAFS (Fig. S11). Similar to C-Fe-Co-ZIF samples, $\mathrm{C}-\mathrm{Cu}-\mathrm{Co}-\mathrm{ZIF}$ samples also exhibit a positive enhancement in $\mathrm{CO}$ production (Fig. S12). $\mathrm{C}-\mathrm{Cu}-\mathrm{Co}-\mathrm{ZIF}-$ $3.2 \mathrm{wt} \%-\mathrm{Cu}$ exhibits the $\mathrm{FE}_{\mathrm{CO}}$ of around $51 \%$ and $\mathrm{FE}_{\mathrm{H} 2}$ of around $37 \%$ at $-0.55 \mathrm{~V}$ versus RHE. The CO current density reaches $8.3 \mathrm{~mA} \mathrm{~cm}-2$ at $-0.7 \mathrm{~V}$ versus RHE. In contrast, $\mathrm{C}-\mathrm{Ni}-\mathrm{Co}-\mathrm{ZIF}$ reveals a negative impact on $\mathrm{CO}$ production (Fig. S13). C-Ni-Co-ZIF-3.2 wt\%-Ni exhibits the $\mathrm{FE}_{\mathrm{CO}}$ of around $35 \%$ and $\mathrm{FE}_{\mathrm{H} 2}$ of around $29 \%$ at $-0.55 \mathrm{~V}$ versus RHE. The CO current density reaches $4.7 \mathrm{~mA} \mathrm{~cm}^{-2}$ at $-0.7 \mathrm{~V}$ versus RHE. It is noted that the total $\mathrm{FE}_{\mathrm{CO}+\mathrm{H} 2}$ of $\mathrm{C}-\mathrm{Ni}-\mathrm{Co}-\mathrm{ZIF}$ does not reach over $70 \%$, indicating a possibly large amount of product formations other than $\mathrm{CO}$ and $\mathrm{H}_{2}$ (Fig. S13d). It implies that $\mathrm{C}-\mathrm{Ni}-\mathrm{Co}-\mathrm{ZIF}$ samples could be more suitable for other $\mathrm{CO}_{2} \mathrm{RR}$ product generations than for syngas production. 


\section{Conclusion}

Atomically dispersed $\mathrm{Fe}$-Co bimetallic catalysts are fabricated by introducing Fe into Co-ZIF along with the pyrolysis. The Fe-Co bimetallic catalysts show excellent activity toward syngas production from $\mathrm{ECO}_{2} \mathrm{RR}$, with tunable $\mathrm{CO} /$ $\mathrm{H}_{2}$ ratios. C-Fe-Co-ZIF-1.6 wt\%-Fe exhibits the highest $\mathrm{FE}_{\mathrm{CO}}$ of $51.9 \%$ and $\mathrm{FE}_{\mathrm{H} 2}$ of $42.4 \%$ at $-0.55 \mathrm{~V}$ vs RHE, where the $\mathrm{FE}_{\mathrm{CO}}$ is significantly increased (around $10 \%$ higher than that of pure $\mathrm{C}-\mathrm{Co}-\mathrm{ZIF})$. The $\mathrm{H}_{2} / \mathrm{CO}$ ratio is tunable in a wide range from 0.8 to 4.2 while maintaining the total $\mathrm{FE}_{\mathrm{CO}+\mathrm{H} 2}$ as high as $93 \%$ for more than $10 \mathrm{~h}$. XAS technique greatly benefits the characterization of the bimetallic atomically dispersed $\mathrm{Fe}-\mathrm{Co}$ catalysts. N K-edge and metal L-edge provide insights into $\mathrm{N}$ species and metal oxidation states in the catalysts. Metal K-edge offers detailed information in the coordination environments of the metal atoms. It confirms that the addition of Fe would interfere with the local coordination environment of $\mathrm{Co}$ in bimetallic catalysts and C-Fe-Co-ZIF-1.6 wt\%-Fe has mild distortions in $\mathrm{Co}$ and $\mathrm{Fe}$ coordination environments. The proper amount of $\mathrm{Fe}$ in $\mathrm{C}-\mathrm{Fe}-\mathrm{Co}-\mathrm{ZIF}-1.6 \mathrm{wt} \%$-Fe increases the number of $\mathrm{M}-\mathrm{N}$ sites and creates mild distortions in the local coordination environment of the metal sites, which is the key reason for the best $\mathrm{CO}$ production performance in $\mathrm{ECO}_{2} \mathrm{RR}$ among all the $\mathrm{C}-\mathrm{Fe}-\mathrm{Co}-\mathrm{ZIF}$ samples. The excessive adding of $\mathrm{Fe}$ results in other product generation than $\mathrm{CO}$ and $\mathrm{H}_{2}$. Applied with the same strategy, atomically dispersed $\mathrm{Cu}-\mathrm{Co}$ bimetallic catalysts also exhibit positive results on $\mathrm{CO}$ production for the syngas generation, while atomically dispersed Ni-Co bimetallic catalysts facilitate other product generations than syngas. The present results demonstrate the synergistic effects concerning the metal combination and the interactions between different metal atoms should be considered for the design of atomically dispersed TM bimetallic catalysts in $\mathrm{ECO}_{2} \mathrm{RR}$.

Acknowledgements This work is supported financially by the Natural Sciences and Engineering Research Council of Canada (NSERC), the Fonds de Recherche du Québec-Nature et Technologies (FRQNT), Centre Québécois sur les Materiaux Fonctionnels (CQMF), the Canada Foundation for Innovation (CFI), and Institut National de la Recherche Scientifique (INRS). The XAS characterizations were performed at the Canadian Light Source (CLS), which is financially supported by NSERC, CFI, the University of Saskatchewan, the Government of Saskatchewan, Western Economic Diversification Canada, the National Research Council of Canada, and the Canadian Institutes of Health Research.
Funding Open access funding provided by Shanghai Jiao Tong University.

Open Access This article is licensed under a Creative Commons Attribution 4.0 International License, which permits use, sharing, adaptation, distribution and reproduction in any medium or format, as long as you give appropriate credit to the original author(s) and the source, provide a link to the Creative Commons licence, and indicate if changes were made. The images or other third party material in this article are included in the article's Creative Commons licence, unless indicated otherwise in a credit line to the material. If material is not included in the article's Creative Commons licence and your intended use is not permitted by statutory regulation or exceeds the permitted use, you will need to obtain permission directly from the copyright holder. To view a copy of this licence, visit http://creativecommons.org/licenses/by/4.0/.

Supplementary Information The online version contains supplementary material available at https://doi.org/10.1007/ s40820-021-00746-9.

\section{References}

1. Z.S. Chen, G.X. Zhang, J. Prakash, Y. Zheng, S.H. Sun, Rational design of novel catalysts with atomic layer deposition for the reduction of carbon dioxide. Adv. Energy Mater. 9(37), 1900889 (2019). https://doi.org/10.1002/aenm.20190 0889

2. Z. Chen, G. Zhang, L. Du, Y. Zheng, L. Sun et al., Nanostructured cobalt-based electrocatalysts for $\mathrm{CO}_{2}$ reduction: Recent progress, challenges, and perspectives. Small 16(52), e2004158 (2020). https://doi.org/10.1002/smll.202004158

3. Y. Zhang, X. Su, L. Li, H. Qi, C. Yang et al., Ru/TiO 2 catalysts with size-dependent metal/support interaction for tunable reactivity in Fischer-Tropsch synthesis. ACS Catal. 10(21), 12967-12975 (2020). https://doi.org/10.1021/acscatal.0c027 80

4. V. Andrei, B. Reuillard, E. Reisner, Bias-free solar syngas production by integrating a molecular cobalt catalyst with

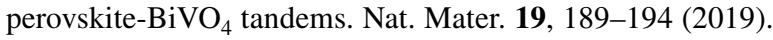
https://doi.org/10.1038/s41563-019-0501-6

5. J. Kang, S. He, W. Zhou, Z. Shen, Y. Li et al., Single-pass transformation of syngas into ethanol with high selectivity by triple tandem catalysis. Nat. Commun. 11(1), 827 (2020). https://doi.org/10.1038/s41467-020-14672-8

6. B. Zhang, B. Zhang, Y. Jiang, T. Ma, H. Pan et al., Single-atom electrocatalysts for multi-electron reduction of $\mathrm{CO}_{2}$. Small 17(36), e2101443 (2021). https://doi.org/10.1002/smll.20210 1443

7. S. Zhu, E.P. Delmo, T. Li, X. Qin, J. Tian et al., Recent advances in catalyst structure and composition engineering strategies for regulating $\mathrm{CO}_{2}$ electrochemical reduction. Adv. Mater. (2021). https://doi.org/10.1002/adma.202005484

8. X. Wang, Z. Chen, X. Zhao, T. Yao, W. Chen et al., Regulation of coordination number over single Co sites: triggering 
the efficient electroreduction of $\mathrm{CO}_{2}$. Angew. Chem. Int. Ed. 57(7), 1944-1948 (2018). https://doi.org/10.1002/anie.20171 2451

9. Z. Zhang, J. Xiao, X.J. Chen, S. Yu, L. Yu et al., Reaction mechanisms of well-defined metal- $\mathrm{N}_{4}$ sites in electrocatalytic $\mathrm{CO}_{2}$ reduction. Angew. Chem. Int. Ed. 57(50), 16339-16342 (2018). https://doi.org/10.1002/anie.201808593

10. H.B. Yang, S.F. Hung, S. Liu, K. Yuan, S. Miao et al., Atomically dispersed $\mathrm{Ni}(\mathrm{I})$ as the active site for electrochemical $\mathrm{CO}_{2}$ reduction. Nat. Energy 3(2), 140-147 (2018). https://doi.org/ 10.1038/s41560-017-0078-8

11. C. Zhang, S. Yang, J. Wu, M. Liu, S. Yazdi et al., Electrochemical $\mathrm{CO}_{2}$ reduction with atomic iron-dispersed on nitrogendoped graphene. Adv. Energy Mater. 8(19), 1703487 (2018). https://doi.org/10.1002/aenm.201703487

12. J. Gu, C.S. Hsu, L. Bai, H.M. Chen, X. Hu, Atomically dispersed $\mathrm{Fe}^{3+}$ sites catalyze efficient $\mathrm{CO}_{2}$ electroreduction to CO. Science 364(6445), 1091-1094 (2019). https://doi.org/ 10.1126/science.aaw7515

13. X. Wang, Z. Wang, Y. Bai, L. Tan, Y. Xu et al., Tuning the selectivity of photoreduction of $\mathrm{CO}_{2}$ to syngas over Pd/layered double hydroxide nanosheets under visible-light up to 600 nm. J. Energy Chem. 46, 1-7 (2020). https://doi.org/10. 1016/j.jechem.2019.10.004

14. W. Zhou, K. Cheng, J. Kang, C. Zhou, V. Subramanian et al., New horizon in $\mathrm{C} 1$ chemistry: breaking the selectivity limitation in transformation of syngas and hydrogenation of $\mathrm{CO}_{2}$ into hydrocarbon chemicals and fuels. Chem. Soc. Rev. 48(12), 3193-3228 (2019). https://doi.org/10.1039/c8cs0 $0502 \mathrm{~h}$

15. J. Long, H. Zhang, J. Ming, J. Zhao, Q. Gu et al., High-rate, tunable syngas production with artificial photosynthetic cells. Angew. Chem. Int. Ed. 58(23), 7718-7722 (2019). https://doi. org/10.1002/anie.201902361

16. S.J. Shen, C. Han, B. Wang, Y.A. Du, Y.D. Wang, Dual active sites-dependent syngas proportions from aqueous $\mathrm{CO}_{2}$ electroreduction. Appl. Catal. B Environ. 279, 119380 (2020). https://doi.org/10.1016/j.apcatb.2020.119380

17. M. Wu, G. Zhang, Y. Hu, J. Wang, T. Sun et al., Graphiticshell encapsulated FeNi alloy/nitride nanocrystals on biomass-derived $\mathrm{N}$-doped carbon as an efficient electrocatalyst for rechargeable Zn-air battery. Carbon Energy 3(1), 176-187 (2020). https://doi.org/10.1002/cey2.52

18. M. Wu, G. Zhang, N. Chen, W. Chen, J. Qiao et al., A selfsupported electrode as a high-performance binder- and carbonfree cathode for rechargeable hybrid zinc batteries. Energy Stor. Mater. 24, 272-280 (2020). https://doi.org/10.1016/j. ensm.2019.08.009

19. C.H. Wu, C. Liu, D. Su, H.L. Xin, H.T. Fang et al., Bimetallic synergy in cobalt-palladium nanocatalysts for $\mathrm{CO}$ oxidation. Nat. Catal. 2(1), 78-85 (2018). https://doi.org/10.1038/ s41929-018-0190-6

20. Z. Kou, X. Li, T. Wang, Y. Ma, W. Zang et al., Fundamentals, on-going advances and challenges of electrochemical carbon dioxide reduction. Electrochem. Energy Rev. (2021). https:// doi.org/10.1007/s41918-021-00096-5
21. Y. Liu, D. Tian, A.N. Biswas, Z. Xie, S. Hwang et al., Transition metal nitrides as promising catalyst supports for tuning $\mathrm{CO} / \mathrm{H}_{2}$ syngas production from electrochemical $\mathrm{CO}_{2}$ reduction. Angew. Chem. Int. Ed. 59(28), 11345-11348 (2020). https://doi.org/10.1002/anie.202003625

22. M.B. Ross, Y. Li, P.D. Luna, D. Kim, E.H. Sargent et al., Electrocatalytic rate alignment enhances syngas generation. Joule 3(1), 257-264 (2019). https://doi.org/10.1016/j.joule.2018.09. 013

23. Q. He, D. Liu, J.H. Lee, Y. Liu, Z. Xie et al., Electrochemical conversion of $\mathrm{CO}_{2}$ to syngas with controllable $\mathrm{CO} / \mathrm{H}_{2}$ ratios over $\mathrm{CO}$ and Ni single-atom catalysts. Angew. Chem. Int. Ed. 59(8), 3033-3037 (2019). https://doi.org/10.1002/anie.20191 2719

24. S.H. Yin, J. Yang, Y. Han, G. Li, L.Y. Wan et al., Construction of highly active metal-containing nanoparticles and FeCo- $\mathrm{N}_{4}$ composite sites for the acidic oxygen reduction reaction. Angew. Chem. Int. Ed. 132(49), 22160-22163 (2020). https://doi.org/10.1002/ange.202010013

25. Sarveena, J.M. Vargas, D.K. Shukla, C.T. Meneses, P.M. Zelis et al., Synthesis, phase composition mossbauer and magnetic characterization of iron oxide nanoparticles. Phys. Chem. Chem. Phys. 18(14), 9561-9568 (2016). https://doi. org/10.1039/c5cp07698f

26. G. Zhang, X. Yang, M. Dubois, M. Herraiz, R. Chenitz et al., Non-PGM electrocatalysts for PEM fuel cells: effect of fluorination on the activity and stability of a highly active $\mathrm{NC} \_\mathrm{Ar}+\mathrm{NH}_{3}$ catalyst. Energy Environ. Sci. 12(10), 30153037 (2019). https://doi.org/10.1039/c9ee00867e

27. Y. Pan, R. Lin, Y. Chen, S. Liu, W. Zhu et al., Design of single-atom Co- $\mathrm{N}_{5}$ catalytic site: a robust electrocatalyst for $\mathrm{CO}_{2}$ reduction with nearly $100 \% \mathrm{CO}$ selectivity and remarkable stability. J. Am. Chem. Soc. 140(12), 4218-4221 (2018). https://doi.org/10.1021/jacs.8b00814

28. T. Schiros, D. Nordlund, L. Palova, D. Prezzi, L. Zhao et al., Connecting dopant bond type with electronic structure in $\mathrm{N}$-doped graphene. Nano Lett. 12(8), 4025-4031 (2012). https://doi.org/10.1021/n1301409h

29. L. Jin, B. Liu, P. Wang, H. Yao, L.A. Achola et al., Ultrasmall Au nanocatalysts supported on nitrided carbon for electrocatalytic $\mathrm{CO}_{2}$ reduction: the role of the carbon support in high selectivity. Nanoscale 10(30), 14678-14686 (2018). https://doi.org/10.1039/c8nr04322a

30. A. Roy, D. Hursán, K. Artyushkova, P. Atanassov, C. Janáky et al., Nanostructured metal-N-C electrocatalysts for $\mathrm{CO}_{2}$ reduction and hydrogen evolution reactions. Appl. Catal. B 232, 512-520 (2018). https://doi.org/10.1016/j.apcatb.2018. 03.093

31. Z. Chen, X. Zhang, W. Liu, M. Jiao, K. Mou et al., Amination strategy to boost $\mathrm{CO}_{2}$ electroreduction current density of $\mathrm{M}-\mathrm{N} / \mathrm{C}$ single-atom catalysts to industrial application level. Energy Environ. Sci. 14(4), 2349-2356 (2021). https:// doi.org/10.1039/d0ee04052e

32. L. Lin, H. Li, C. Yan, H. Li, R. Si et al., Synergistic catalysis over iron-nitrogen sites anchored with cobalt phthalocyanine 
for efficient $\mathrm{CO}_{2}$ electroreduction. Adv. Mater. 31(41), e1903470 (2019). https://doi.org/10.1002/adma.201903470

33. W. Ren, X. Tan, W. Yang, C. Jia, S. Xu et al., Isolated diatomic Ni-Fe metal-nitrogen sites for synergistic electroreduction of $\mathrm{CO}_{2}$. Angew. Chem. Int. Ed. 58(21), 6972-6976 (2019). https://doi.org/10.1002/anie.201901575

34. V.V. Mesilov, V.R. Galakhov, A.F. Gubkin, E.A. Sherstobitova, G.S. Zakharova et al., X-ray diffraction and X-ray spectroscopy studies of cobalt-doped anatase $\mathrm{TiO}_{2}$ : Co nanopowders. J. Phys. Chem. C 121(43), 24235-24244 (2017). https://doi.org/10.1021/acs.jpcc.7b05873

35. X. Yang, M. Wang, M.J. Zachman, H. Zhou, Y. He et al., Binary atomically dispersed metal-site catalysts with coreshell nanostructures for $\mathrm{O} 2$ and $\mathrm{CO} 2$ reduction reactions. Small Sci. (2021). https://doi.org/10.1002/smsc.202100046

36. W.T. Chen, C.W. Hsu, J.F. Lee, C.W. Pao, I.J. Hsu, Theoretical analysis of Fe k-edge XANES on iron pentacarbonyl.
ACS Omega 5(10), 4991-5000 (2020). https://doi.org/10. 1021/acsomega.9b03887

37. H. Dong, L. Zhang, L. Li, W. Deng, C. Hu et al., Abundant $\mathrm{Ce}^{3+}$ ions in $\mathrm{Au}-\mathrm{CeO}$ nanosheets to enhance $\mathrm{CO}_{2}$ electroreduction performance. Small 15(17), e1900289 (2019). https:// doi.org/10.1002/smll.201900289

38. G.W. Woyessa, J.B. Cruz, M. Rameez, C.H. Hung, Nanocomposite catalyst of graphitic carbon nitride and $\mathrm{Cu} / \mathrm{Fe}$ mixed metal oxide for electrochemical $\mathrm{CO}_{2}$ reduction to $\mathrm{CO}$. Appl. Catal. B 291, 120052 (2021). https://doi.org/10.1016/j.apcatb. 2021.120052

39. J. Wang, S. Kattel, C.J. Hawxhurst, J.H. Lee, B.M. Tackett et al., Enhancing activity and reducing cost for electrochemical reduction of $\mathrm{CO}_{2}$ by supporting palladium on metal carbides. Angew. Chem. Int. Ed. 58(19), 6271-6275 (2019). https://doi. org/10.1002/anie.201900781 